\title{
Experimental evidence of a two-axial groove hydrodynamic journal bearing under severe operation conditions
}

\author{
Steven Chatterton ${ }^{1}$, Phuoc Vinh Dang ${ }^{1,3}$, Paolo Pennacchi ${ }^{1}$, A. De Luca², F. Flumian² \\ ${ }^{1}$ Politecnico di Milano, Dept. Mechanical Engineering, Via La Masa 1, 20156 Milano, Italy \\ ${ }^{2}$ Danieli \& C Officine Meccaniche S.p.A., Research \& Development, Via Nazionale 41, 33042 \\ Buttrio (UD), Italy \\ ${ }^{3}$ Department of Mechanical Engineering, The University of Danang-University of Science and \\ Technology, 54, Nguyen Luong Bang Street, Danang, Viet Nam.
}

\begin{abstract}
In this study, an experimental investigation of the influence of the applied static load and rotational speed on the behavior of a 160-mm diameter cylindrical journal bearing with two axial grooves was conducted. The rotational speed ranged from $66 \mathrm{rpm}$ to $1440 \mathrm{rpm}$, and the applied static load varied from $0 \mathrm{kN}$ to $350 \mathrm{kN}$ in the vertical direction. The profiles of the pressure and the oil-film thickness during the shaft rotation have been measured by one proximity probe and one pressure probe installed in the rotating shaft. Measurements of the shaft centre position, dynamic coefficients, hydrodynamic pressure, temperature distributions on the bearing, film thickness, and bearing deformation under several operating conditions are presented and discussed.
\end{abstract}


NOMENCLATURE

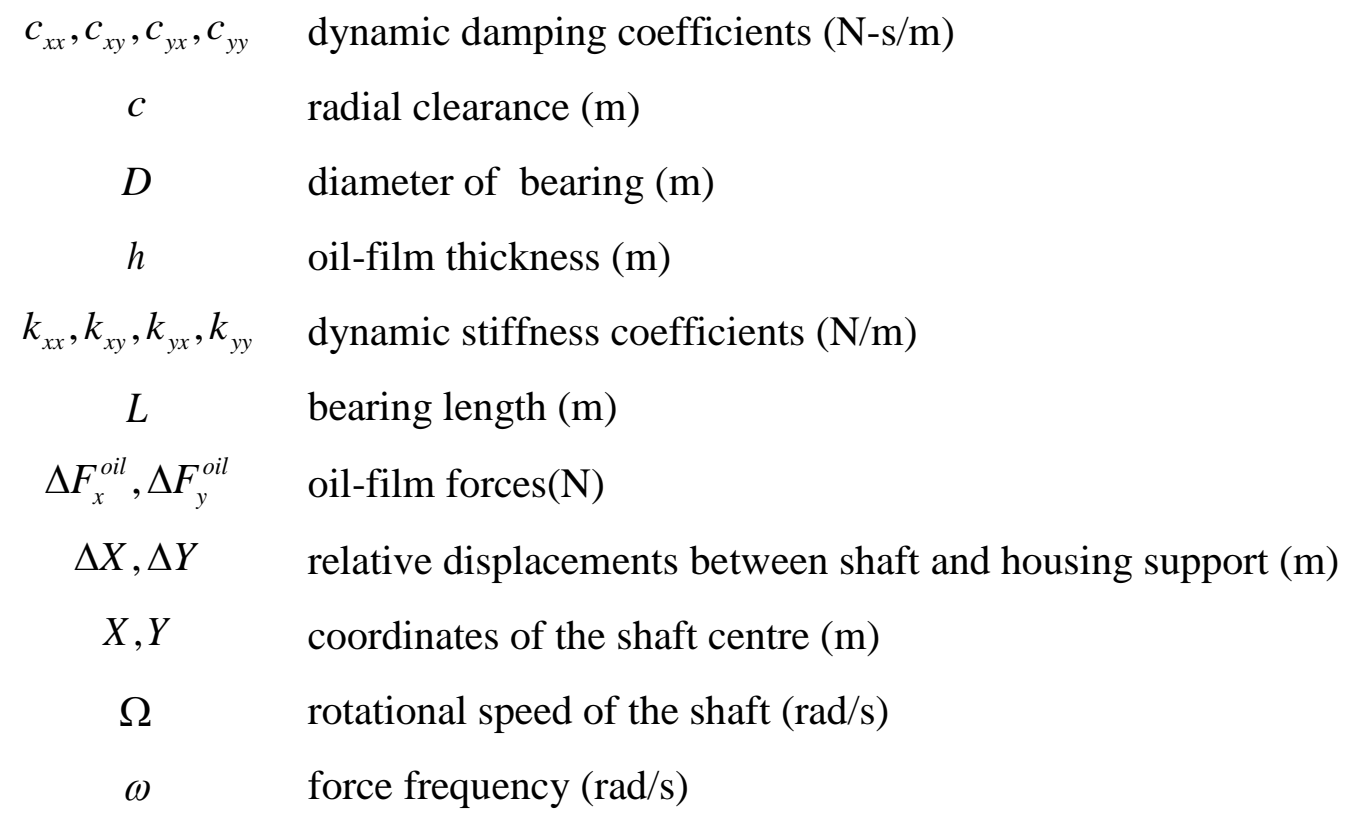




\section{INTRODUCTION}

The installation of oil-film plain journal bearings in industrial machines remains a good choice because of their simplicity and low cost compared to rolling element bearings or oil-film TPJBsTilting-pad Journal Bearings. Typical applications include reciprocating machines with small diameter shafts, operating at high speeds, where the high dynamic behaviours offered by other bearing types are not required. Critical applications are represented by machines with medium/large diameter shafts, operating at very low Sommerfeld numbers and characterized by both low tangential speeds (less than $1 \mathrm{~m} / \mathrm{s}$ ) and high loads (specific pressure higher than $10 \mathrm{MPa}$ ). High viscosity oils are usually employed in these cases (ISO VG grade higher than 100).

In this condition, the so-called mixed or partial lubrication occurs, and the use of simple models, such as hydrodynamic (HD) or thermo-hydrodynamic (THD) during the design phase could lead to the oversizing of the bearing, mainly because of the overestimation of the maximum value of the oil-film pressure. Thermo-elasto-hydrodynamic models (TEHD), improve the prediction of the pressure distribution by considering the bearing deformation under large loads.

The thermal behaviours of a cylindrical journal bearing have been widely studied for several decades. THD and TEHD models as well as experimental activities have been performed to fully understand the behaviour of oil-lubricated [1]-[10] 
studied the behaviour of a journal bearing as a function of the rotational speed and applied static load. The test bearing had a diameter of $100 \mathrm{~mm}$ with two axial grooves placed at $\pm 90^{\circ}$ with reference to the direction of applied static load. The maximum operating conditions were $10 \mathrm{kN}$ for the load and $4000 \mathrm{rpm}$ for the rotational speed. They stated that the journal temperature, the maximum bush temperature and the flow-rate increased linearly with the increase in the rotational speed. In particular, the rising of the static load leaded to the increase of the temperature in the loaded part and the decrease of the temperature in the unloaded part of the bearing, but it did not appear to significantly affect the temperature of the rotating shaft and the oil outlet.

Wang and Khonsari [23]-[24] used an analytical solution to study the impact of oil inlet pressure and the position of an axially grooved oil supply hole. The Reynolds-Floberg-Jakobsson boundary conditions were assumed to recognize the starting position of the cavitation, the reformation of oil film at the end of cavitation, and the effect of oil inlet pressure and inlet position. It was discovered that the oil inlet pressure had a pronounced impact on the oil film configuration 
and pressure distribution. With increasing oil inlet pressure, the cavitation region shrinks and the peak hydrodynamic pressure increases.

\section{Gardner}

determined experimentally the conditions under which the transition from full hydrodynamic film to boundary lubrication occurred in journal bearings. He performed the tests with a two grooves sleeve type and a TPJB for 13" diameter shaft. He concluded that the lower limit of hydrodynamic lubrication corresponds to the Sommerfeld number between 0.005 and 0.006 . By experimental tests, he detected that the definite movement of the Babbitt metal (wiping) will occur when the applied static load is above 750 psi and only light polishing of the Babbitt developed in the matter of the applied load is up to 300 psi.

The effect of oil groove location was studied in the experimental work conducted by Ahmad et al.

a 100mm-diameter journal bearing. The groove was positioned at seven different locations, namely $-45^{\circ},-30^{\circ},-15^{\circ}, 0^{\circ},+150,+30^{\circ}$ and $+45^{\circ}$. It was discovered that the changes of the oil groove location affected the temperature and pressure to some extent. A THD was considered in [27]-

Ref456621572 $\mathrm{Vr} \backslash \mathrm{h}[28]$ for the effect of the oil groove location. 
In

and

[30],

the

mixed lubrication of a small bearing running at low rotational speed from 2 to $500 \mathrm{rpm}$ with different oil temperatures and applied loads were investigated. In the mixed lubrication regime, the higher lubricant temperature leads to a large friction coefficient. The Sommerfeld number is less than 0.002 in this condition.

Allmaier [32] et extended al.

a
TEHD

model from an EHD model to study the differences arising from local temperatures in the journal bearings. With suitable thermal boundary conditions, it should be noted that the TEHD model is able to forecast the occurring temperatures at some different points of the test-rig with very high accuracy.

In

and

[34],

the

friction and mixed lubrication regime in journal bearings were investigated numerically and experimentally for a large range of operating conditions, lubricants (SAE10, SAE20, SAE30 and 
SAE40), and rotational speeds from hydrodynamic lubrication regime to mixed lubrication regime with metal-metal contact.

In the present study, extensive experimental work has been conducted to determine the static and the dynamic behaviour of a plain journal bearing working at different operating conditions, namely static load and rotational speed. For confidential reasons, all data have been omitted as well as some results have been normalized with reference to the corresponding maximum value.

\section{TEST RIG AND BEARING DESCRIPTION}

The test-rig for characterization of the plain journal bearing is illustrated in Fig. 1a. A $15.0 \mathrm{~kW}$ electric motor drives the rigid shaft by through a flexible coupling. The motor speed is adjusted by a frequency controller and can reach a maximum value of $1465 \mathrm{rpm}$. The shaft speed can also be reduced by installing the additional gearbox with a gear ratio of 1:9. The vertical static load is applied on the top of the bearing case through two hydraulic actuators placed in the vertical direction and working in parallel with the maximum force of $400 \mathrm{kN}$. This load corresponds to the very high specific pressure of approximately $17 \mathrm{MPa}$ compared to the common values of approximately 2-3 MPa adopted in the industrial field. The vertical static load acting on the housing support is in the downward direction corresponding to a load applied on the shaft in the upward direction. The test rig is also equipped with a hydraulic actuator (maximum force equal to $20 \mathrm{kN}$ ) placed in the orthogonal direction (horizontal) respecting to the two vertical actuators. The static force in the horizontal direction is given by the horizontal actuator and it has been set equal to zero during the tests described in the paper. Conversely dynamics load along several directions are generated by the horizontal and vertical actuators and applied to the bearing in order to evaluate the dynamic coefficients of the bearing system. Note that all the actuators can generate both static and dynamic loads at the same time.

The approximated sketch of the test bearing is shown in Fig. 1b. The bearing, which is centrally placed on the rotating 
shaft, has the nominal diameter $D$ of $160 \mathrm{~mm}$ and the length $L$ of $145 \mathrm{~mm}$. The bearing has a thickness of about $5 \mathrm{~mm}$ and mainly consists of a base steel part. The inner surface of the bearing is covered by a layer of $1 \mathrm{~mm}$ of anti-friction alloy $(\mathrm{CuPbSn})$ having an average surface roughness of $R a=0.8 \mu \mathrm{m}$. The shaft rotates in a counter-clockwise direction from non-driven end (NDE) view and the vertical static load, as already stated, is applied on the shaft in the upward direction.

The bearing has two axial grooves located in the lower part (unloaded part). An additional groove in the circumferential direction is placed at the centre of the axial direction of the bearing and connects the two axial grooves. The oil enters from the inlet hole and fills all the grooves during the shaft rotation. The resulting angular span of the loaded part of the bearing (upper part) is $\begin{array}{lllll}\text { equal to } & \text { about } & 205^{\circ} & \text { (see } & \text { Fig. } 1\end{array}$ b). The real application of this bearing is in rolling mills of steel plants. The design has been optimized by the manufactured for improving the lubrication of the bearing under the severe operating conditions of the actual application.

In the test rig, the bearing is installed by interference in the bearing ring having a thickness of about $45 \mathrm{~mm}$ as shown in Fig. 4b. An anti-rotation pin between the bearing and the bearing ring (see is additionally installed for safety reasons. The bearing ring has several holes for the measuring probes. Then the profile of the inner surface of the bearing has been measured by means of the ZEISS PRISMO bridge-type CMMs scanning machine in order to measure the actual diameter of the bearing after its installation in the bearing ring and any possible deformation occurred during the coupling. The deviation of the bearing profile from the nominal value after the installation of the bearing in the bearing ring is shown in Fig. 2 in which the profile has been measured in correspondence of the NDE edge (the same position of the rotating proximity probe shown in Fig. 5). In Fig. 2 it is possible to see a light deformation of the actual bearing profile that is also higher than the nominal one. 
The bearing ring is then installed in the housing support that is composed of two parts, one of them shown in Fig. 3b. The actuators are directly connected to the housing support.

The bearing ring is equipped with one fixed pressure probe which is installed at the centre of the axial direction and $15^{\circ}$ from the vertical direction (see Fig. 3a). Only the loaded part of the plain journal bearing is instrumented by the nine temperature probes (see Fig. 4), which are installed at a distance of $L / 4$ from the centre of the bearing close to the NDE side and are equally spaced by $22.5^{\circ}$ along half of the circumference (T1 and T9 are along the horizontal direction).

The two proximity probes $\mathrm{XC}$ and $\mathrm{YC}$ are installed at $45^{\circ}$ apart in the vertical direction on the bearing ring and are used to measure the centre position of the shaft at the centre of the axial direction. In particular the holes of these sensors are placed in the circumferential groove of the bearing (Fig. 3a). Four proximity probes, labelled as XDE, YDE, XNDE and YNDE are installed at $45^{\circ}$ apart in the vertical direction on the housing support in both the driven end (DE) and the NDE side (see Fig. 3b). In particular each couple of these probes (XDE/YDE and XNDE/YNDE) is installed in the same configuration of the $\mathrm{XC} / \mathrm{YC}$ probes but in a parallel plane at a distance of $85 \mathrm{~mm}$ from the centre of the bearing.

The four proximity probes are still used to measure the centre position of the shaft but are also able to detect the angular misalignment between the shaft and the housing support. Theoretically without angular misalignment and deformations the same shaft centre position should be obtained by the three couples of proximity probes.

A proximity sensor is used as a key phasor to perform the synchronous averaging and to detect the rotational speed. Two accelerometers (horizontal and vertical) are installed on the case of bearing and used to compensate inertial forces in the estimation of the dynamic coefficients. 


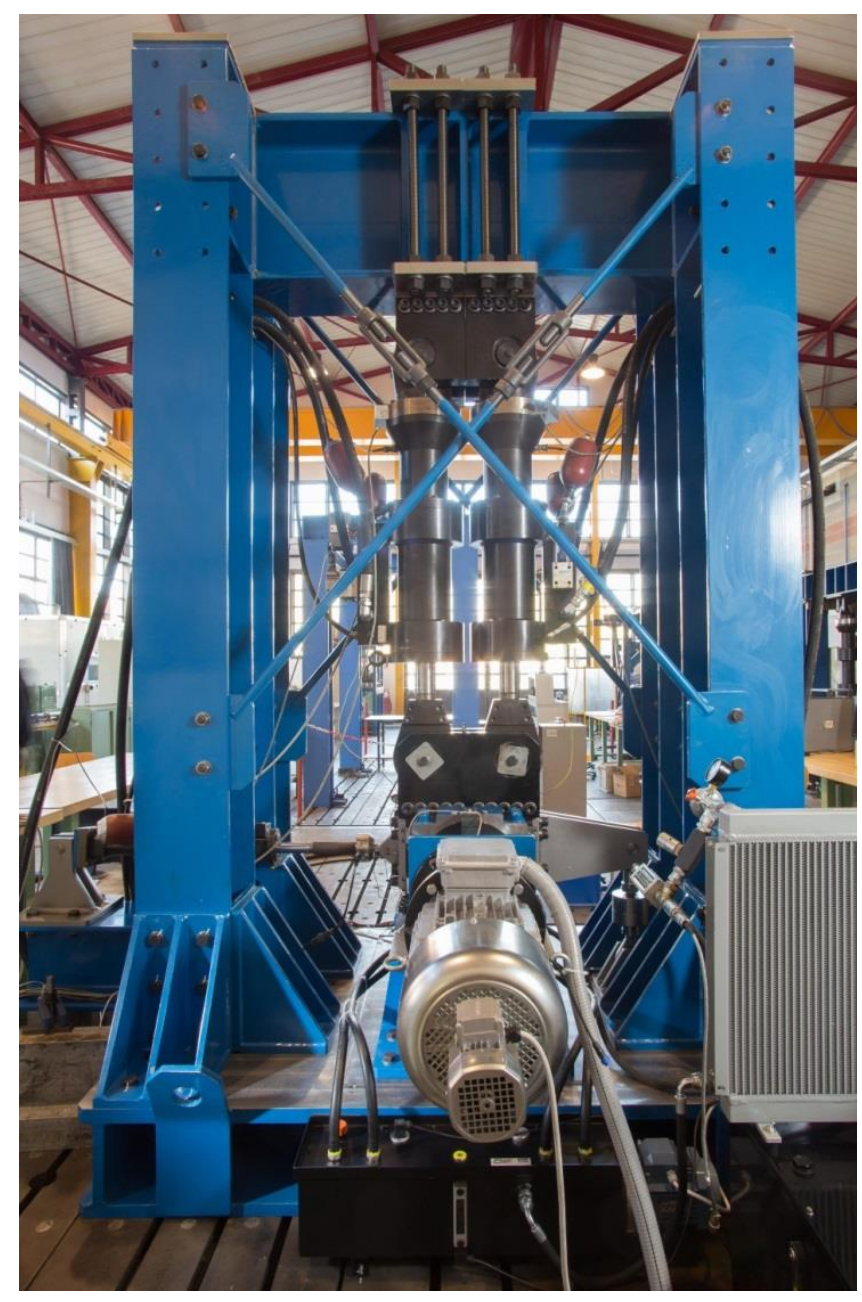

(a)

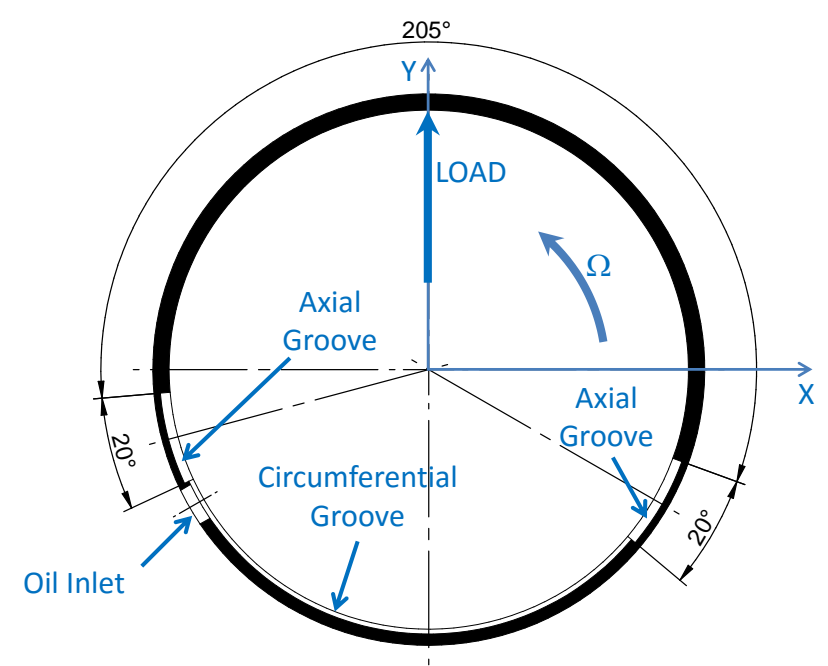

(b)

Fig. 1. Test-rig from the DE side view (a) and sketch of bearing under test from NDE view (b). 


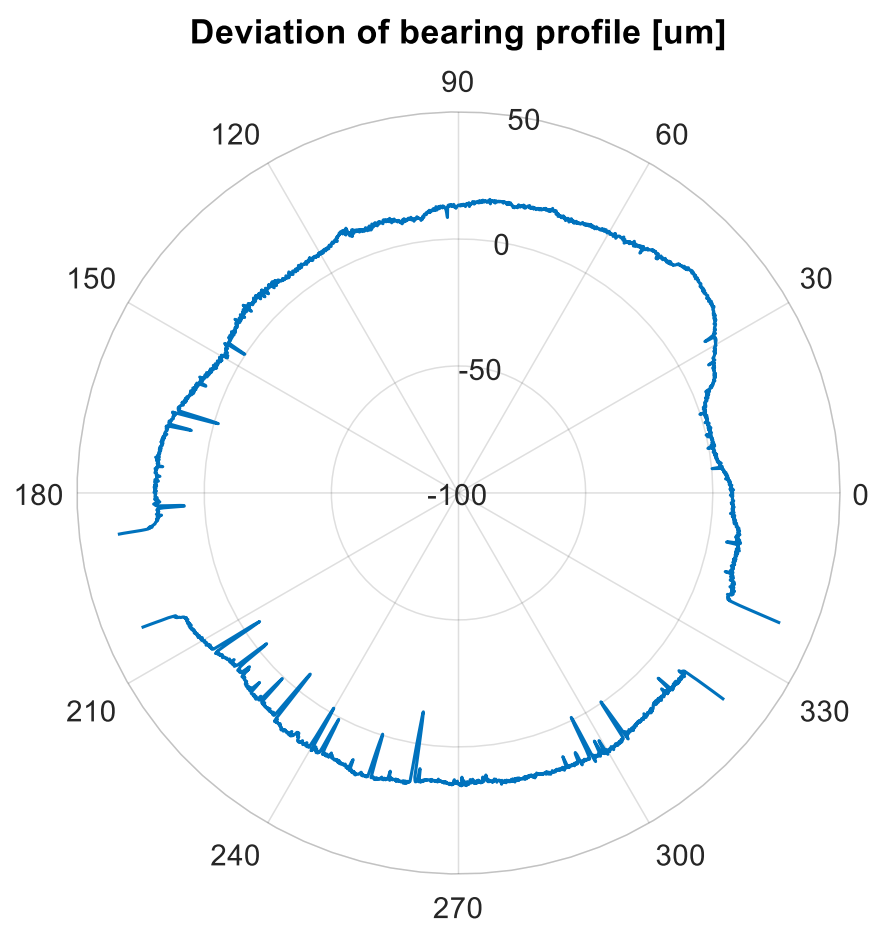

Fig. 2. Deviation in microns of the bearing profile from the nominal value after the installation in the bearing ring in correspondence of the NDE edge.

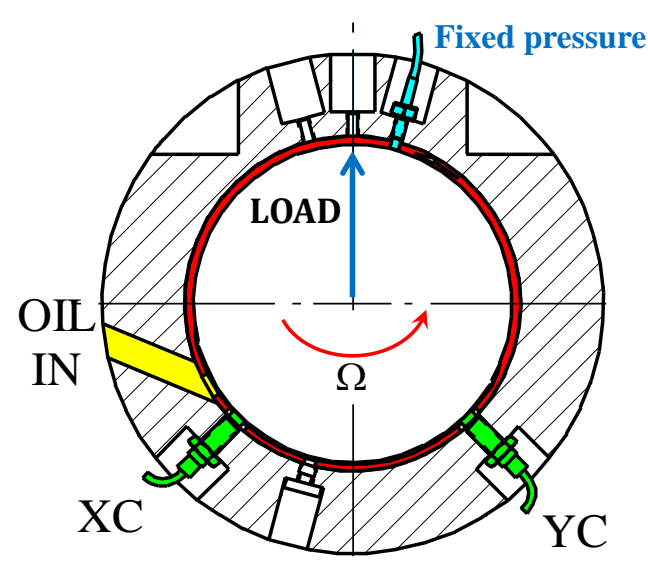

(a)

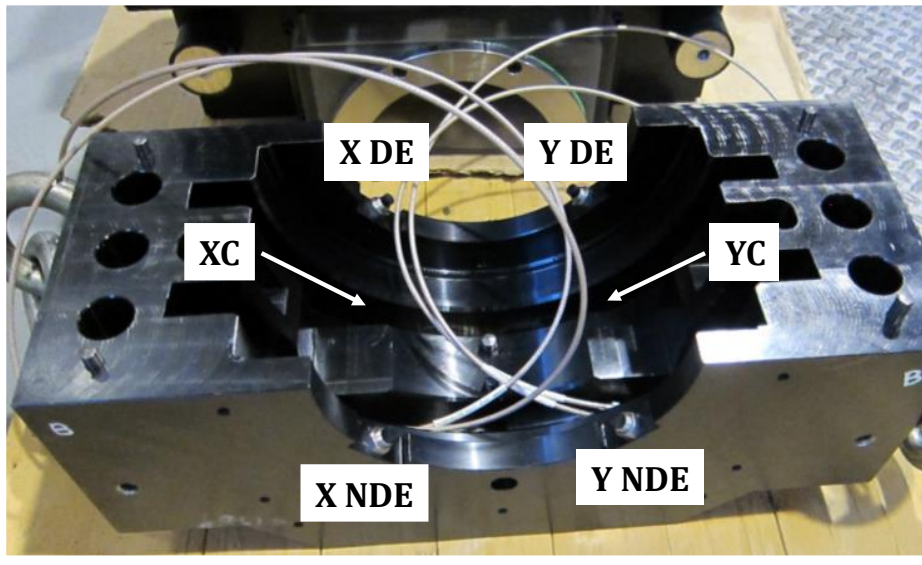

(b)

Fig. 3. Installed sensors: (a) two proximity probes and a fixed pressure probe are placed at the centre of the axial direction and (b) four proximity probes are installed on the bearing case in both

$\mathrm{DE}$ and NDE view and corresponding positions of two proximity probes ( $\mathrm{XC}$ and $\mathrm{YC}$ ) after assembly the bearing system. 


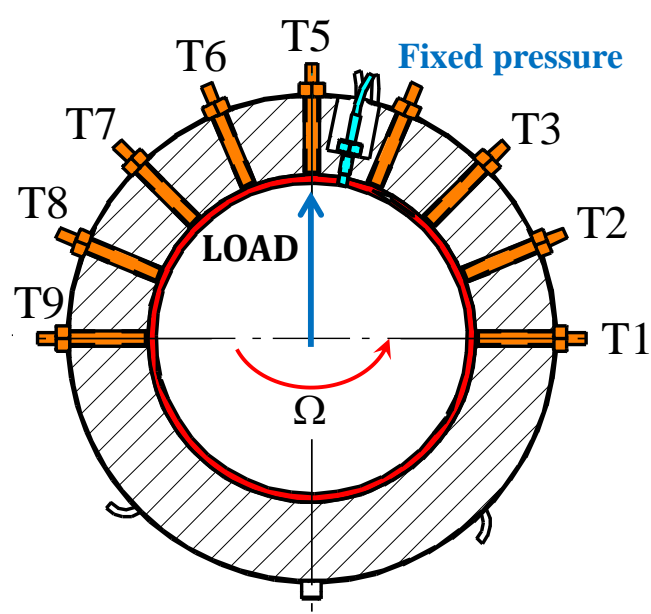

(a)

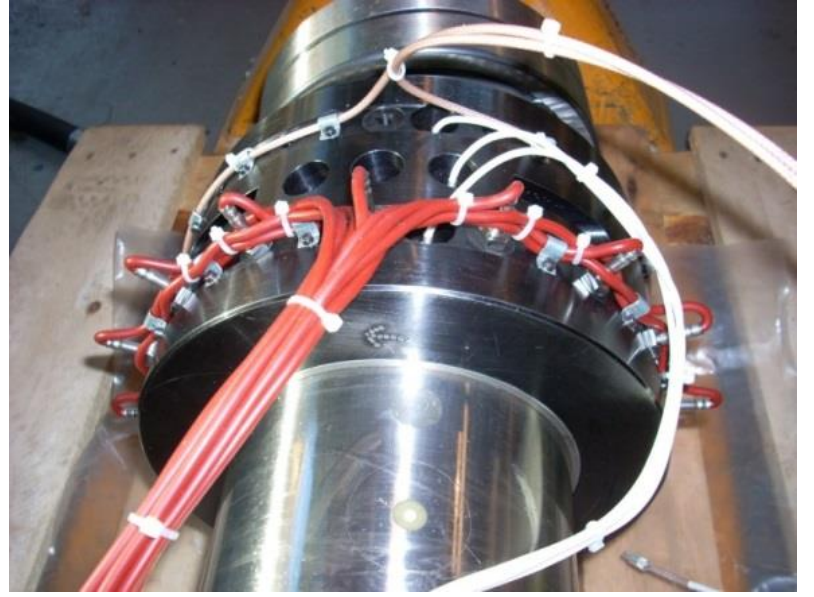

(b)

Fig. 4. Temperature probes are installed on the loaded part of the bearing.

The shaft is made of $17 \mathrm{NiCrMo6}-4$ steel and has an average surface roughness equal to $R a=0.2 \mu \mathrm{m}$ obtained by grinding after surface hardening. This shaft is equipped with one pressure probe and one proximity probe for measuring the pressure and the oil film thickness during the shaft rotation. The pressure probe is installed in correspondence of the centre of the bearing. The proximity probe is installed close to the edge of the bearing along the axial direction (see Fig. 5).

The pictures of the pressure and proximity probes installed inside the shaft after grinding are represented in Fig. 6.

The signals of these sensors are transmitted through a slip-ring device (see 
f456375574 ih $\quad$ t $*$ MERGEFORMAT Fig. 7). The details regarding the test bearing dimensions, lubricant properties and operating parameters are given in

$\mathrm{F}$

Ref

438

128

285

lh

1

$* \mathrm{M}$

ERG

EFO

RMA

$\mathrm{T} \mathrm{Tab}$

le 1 . 


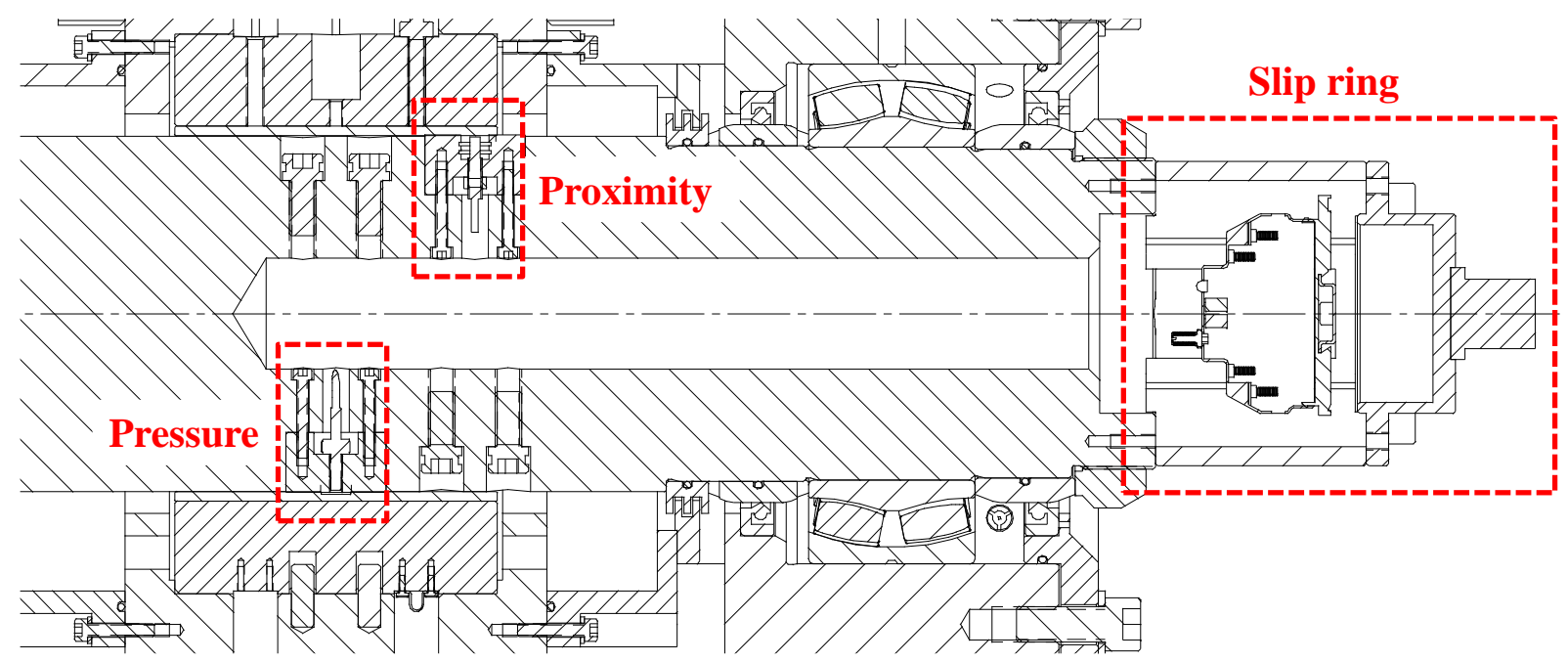

Fig. 5. Sketch of the hollow shaft instrumented with a proximity probe, a pressure probe, and a slip ring device for transmission of signals.

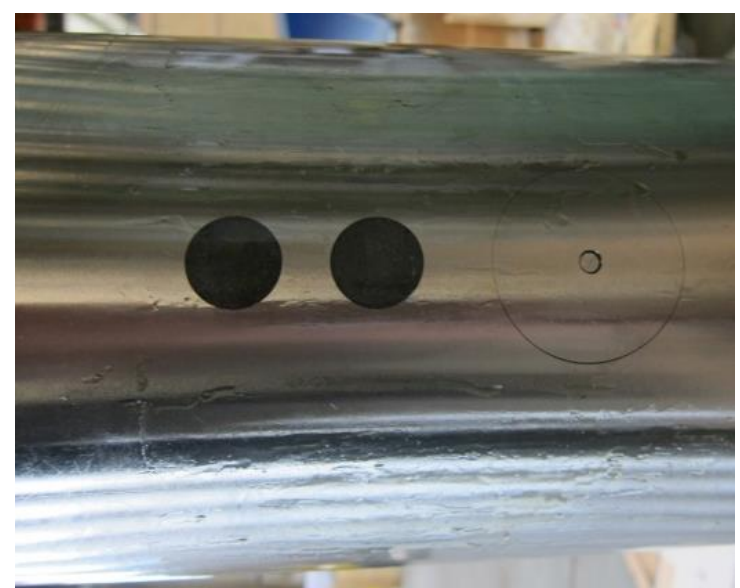

(a)

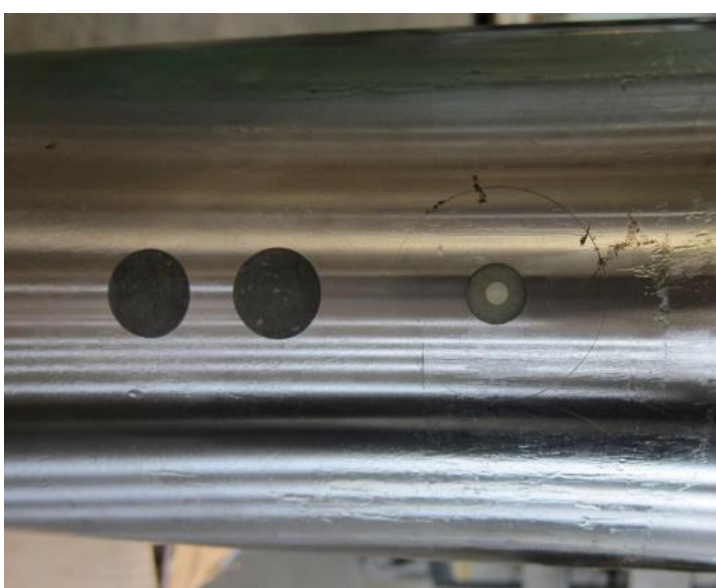

(b)

Fig. 6. Pressure probe (a) and proximity probe (b) installed in the shaft after grinding. 


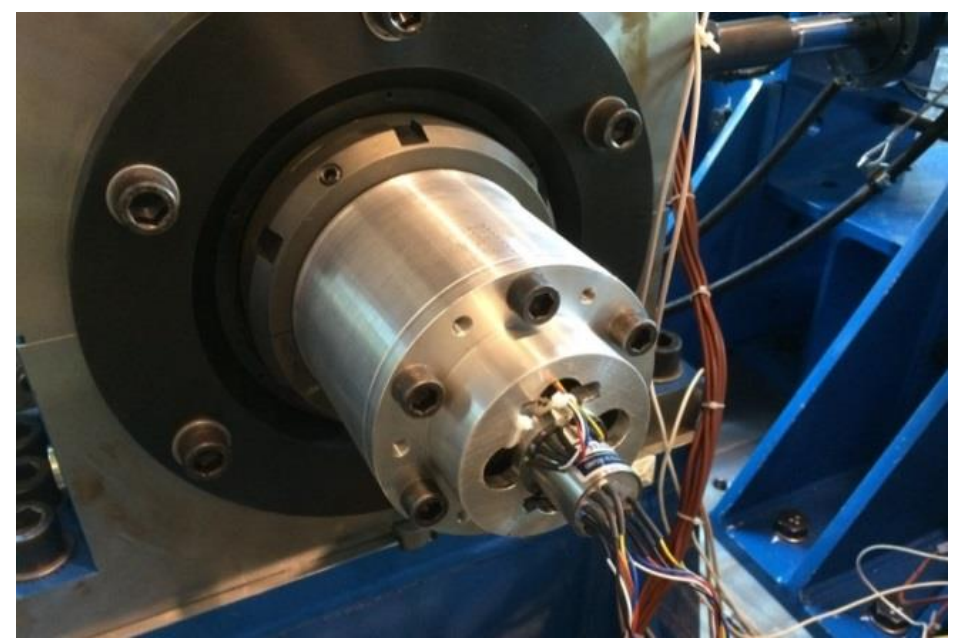

Fig. 7. Slip ring device at the NDE side of the shaft.

Table 1. Main dimensions of journal bearing, lubricant properties and installed sensors.

\begin{tabular}{ll}
\hline Parameter & Value \\
\hline Bearing diameter, $D$ & $160 \mathrm{~mm}$ \\
Bearing length, $L$ & $145 \mathrm{~mm}$ \\
Applied load, $W$ & $0-350 \mathrm{kN}$ \\
Journal speed, $\Omega$ & $1 \mathrm{~Hz}-24 \mathrm{~Hz}$ \\
Lubricant type & ISO VG150 \\
Pressure probe & \\
Model & MEAS XPM6 $-1 \mathrm{KBS}$ \\
Range & $1000 \mathrm{bars}$ \\
Accuracy & $\pm 0.25 \% \mathrm{~F} \cdot \mathrm{S}$ \\
Temperature probe & \\
Model & PT 100 \\
Range & $-40-120{ }^{\circ} \mathrm{C}$ \\
Accuracy & $\pm 1 \%$ measured temperature \\
Fixed proximity probe & \\
Model & CEMB T-NC/8-API \\
Range & \pm 1 mm \\
Accuracy & $\pm 1 \%$ measured value \\
Rotating proximity system & \\
Sensor & KAMAN $5 \mathrm{U} / \mathrm{KD}-2446$ \\
Resolution & $<0.008 \%$ of the measured range \\
Thermal drift & $<0.22 \%$ per ${ }^{\circ} \mathrm{C}$ of full scale for \\
\hline & the sensor \\
\hline
\end{tabular}




\section{EXPERIMENTAL RESULTS}

In this paper, several tests at different static loads and rotational speeds were performed to study the behaviour of the plain journal bearing. During the tests, the oil inlet was kept at approximately $40{ }^{\circ} \mathrm{C}$ using a closed-loop PI temperature control.

After the tests the bearing has been disassembled from the shaft for a visual inspection. In particular there were no significant signs on the shaft and on the bearing surface. Therefore metalmetal contact did not occur during the tests. Only small signs in correspondence of the hole of the fixed pressure probe have been detected, probably due to a local deformation of the anti-friction material.

For confidential reasons, all results concerning the dynamic coefficients, temperature profiles of the bearing, shaft centre position, hydrodynamic pressure distribution, oil film thickness and bearing deformation are normalized with reference to the maximum ones.

\subsection{Dynamic coefficients}

The linearized coefficients are experimentally evaluated by applying dynamic loads in several directions

load (see Fig. 8) in

addition

to

the

static

load

[35]-

F

Ref

456

599

968 


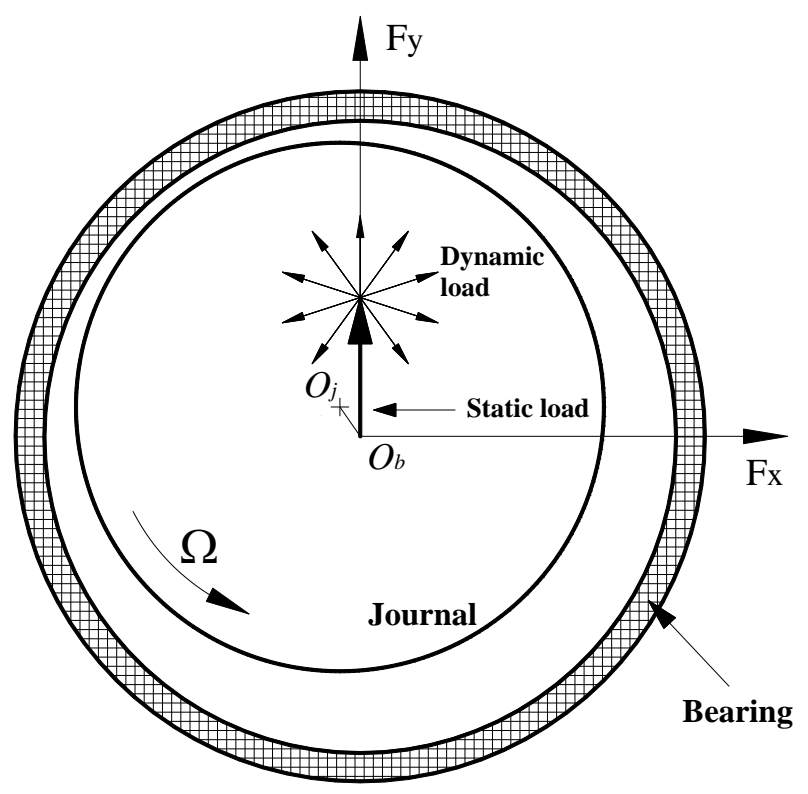

Fig. 8. Applied loads for the experimental evaluation of the linearized coefficients.

For the $k$-th direction of the excitation, the oil-film forces, $\Delta F_{x}^{o i l}(\omega)-\Delta F_{y}^{o i l}(\omega)$ in the frequency domain are given by:

$$
\left[\begin{array}{c}
\Delta F_{x}^{o i l}(\omega) \\
\Delta F_{y}^{o i l}(\omega)
\end{array}\right]_{k}=\left[\begin{array}{ll}
h_{x x}(\omega) & h_{x y}(\omega) \\
h_{y x}(\omega) & h_{y y}(\omega)
\end{array}\right]_{k}\left[\begin{array}{l}
\Delta X(\omega) \\
\Delta Y(\omega)
\end{array}\right]_{k}
$$

where $\Delta X(\omega)-\Delta Y(\omega)$ represent the displacements, $h_{x y}(\omega)=k_{x y}(\omega)+\mathrm{i} \omega c_{x y}(\omega)$ is the generic dynamic coefficients, including the stiffness coefficients and damping coefficients, and $\omega$ is the 
dynamic force frequency. By taking into account all the directions of the excitation ( $N$ directions), eq. (1) can be expressed as:

$$
\Delta \mathbf{F}=\left[\begin{array}{c}
{\left[\Delta F_{1}(\omega)\right]} \\
{\left[\Delta F_{2}(\omega)\right]} \\
\mathbf{M} \\
{\left[\Delta F_{N}(\omega)\right]}
\end{array}\right]=\left[\begin{array}{c}
{\left[R_{1}(\omega)\right]} \\
{\left[R_{2}(\omega)\right]} \\
\mathbf{M} \\
{\left[R_{N}(\omega)\right]}
\end{array}\right]\left[\begin{array}{l}
h_{x x}(\omega) \\
h_{x y}(\omega) \\
h_{y x}(\omega) \\
h_{y y}(\omega)
\end{array}\right]=[\mathbf{R}] \mathbf{h}
$$

where

$$
\left[R_{k}(\omega)\right]=\left[\begin{array}{cccc}
\Delta X(\omega) & \Delta Y(\omega) & 0 & 0 \\
0 & 0 & \Delta X(\omega) & \Delta Y(\omega)
\end{array}\right]_{k}
$$

The dynamic coefficients vector $\mathbf{h}$ has been obtained in Eq. $9436 \quad$ ih (2) by using a robust M-estimator technique REF_Ref456619523 Ir lh [40]. Lastly, the dynamic coefficients, neglecting the virtual mass coefficients in the stiffness terms, can be estimated as:

$$
\begin{gathered}
k_{i j}=\operatorname{Re}\left[h_{i j}\right] \\
c_{i j}=\frac{\operatorname{Im}\left[h_{i j}\right]}{\omega}
\end{gathered}
$$

where $i, j=x, y$. 
The normalized direct and cross dynamic coefficients are shown in $62820 \quad \mathrm{~h} \quad l^{*}$ MERGEFORMAT Fig. 9, where the experimental values are plotted with marks, and the corresponding fitting curves are plotted with dashed lines. In Fig. 9 the rotor speed is $66 \mathrm{rpm}$, the force frequency is $1.5 \mathrm{~Hz}$ and the dynamic load is $3 \mathrm{kN}$.

It is clearly seen that the dynamic direct stiffness coefficients strongly depend on the applied static load, especially the stiffness coefficients in the loaded direction $\left(k_{y y}\right)$. This coefficient increases significantly when the applied static load increases from $20 \mathrm{kN}$ to $350 \mathrm{kN}$. Note that the values of the stiffness coefficient in the loaded direction $\left(k_{y y}\right)$ are greater than those in the orthogonal unloaded direction $\left(k_{x x}\right)$, particularly at high static load. The cross-term of stiffness coefficients $\left(k_{x y}\right.$ and $k_{y x}$ ) are much smaller than the direct-term of stiffness coefficients and are not very sensitive to the static load. 

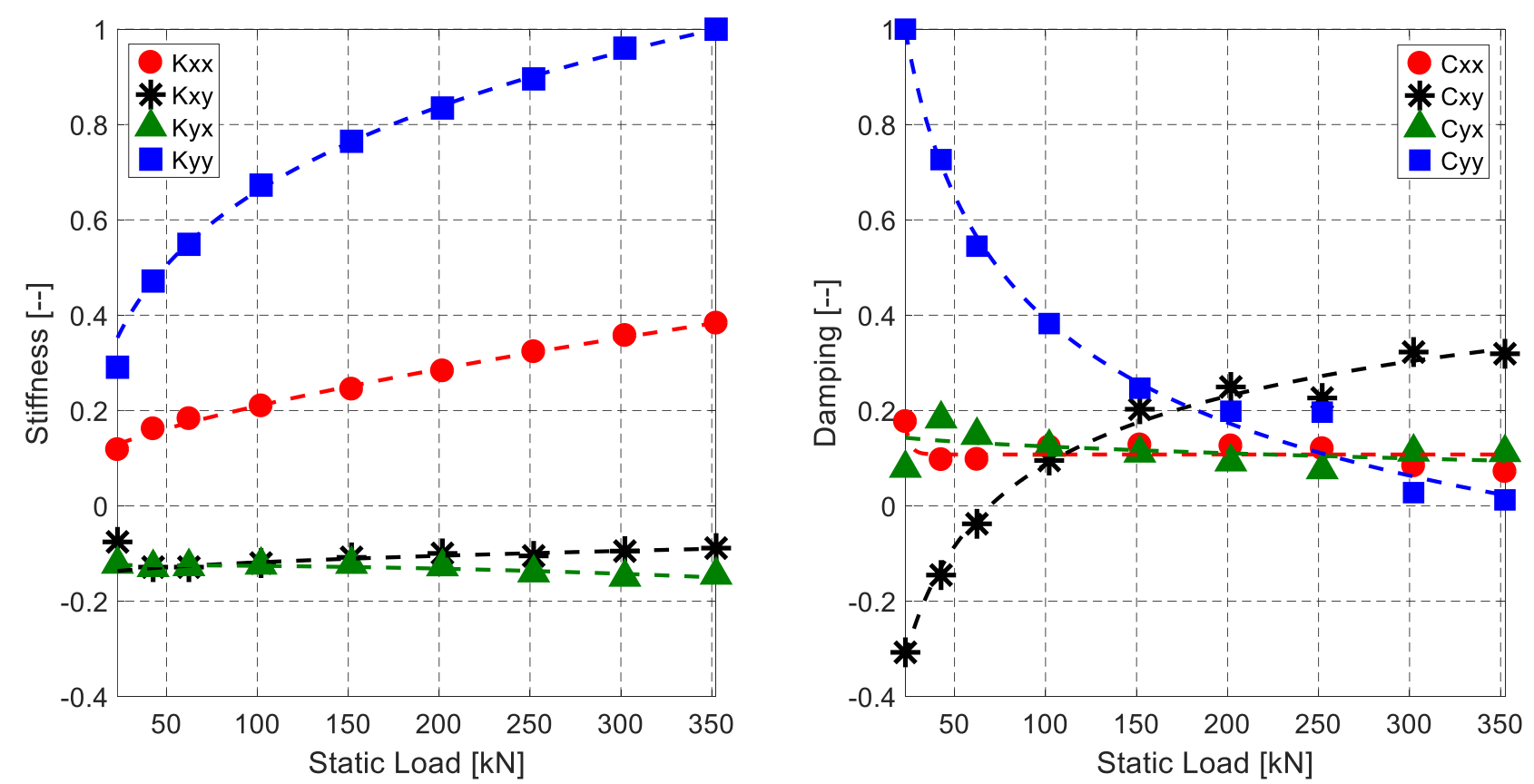

Fig. 9. Dynamic coefficients vs. static load at a speed of $66 \mathrm{rpm}$.

An opposite trend is shown for the direct damping coefficient in the loaded direction $\left(c_{y y}\right)$, which decreases dramatically with the increase of the applied static load. Note that whilst the crosscoupled damping coefficient $\left(c_{y x}\right)$ appears to be constant with the static load, the other cross coefficient $\left(c_{x y}\right)$ shows a remarkable dependence on the applied load.

Fig. 10

shows the normalized dynamic coefficients as a function of the rotational speed at the constant static load of $80 \mathrm{kN}$. As shown in the Fig. 10, the direct stiffness coefficient in the unloaded direction $\left(k_{x x}\right)$ 
decreases more or less linearly from 0.21 to 0.14 with increasing speed, whereas $k_{y y}$ shows a contrary trend. The value of $k_{y y}$ increases from 0.41 to approximately 0.55 when the rotational speed increases from $5 \mathrm{~Hz}$ to $23.4 \mathrm{~Hz}$. The cross-terms of the stiffness coefficients are much smaller than the direct coefficients. However, these coefficients are quite stable with the variation of the shaft speed.

An opposite trend is presented for the direct damping coefficients $c_{x x}$ and $c_{y y}$. While $c_{y y}$ decreases dramatically with the increase of the rotational speed from 0.4 to less than 0.1 , the value of $c_{x x}$ does not appear to be affected by the rotational speed.
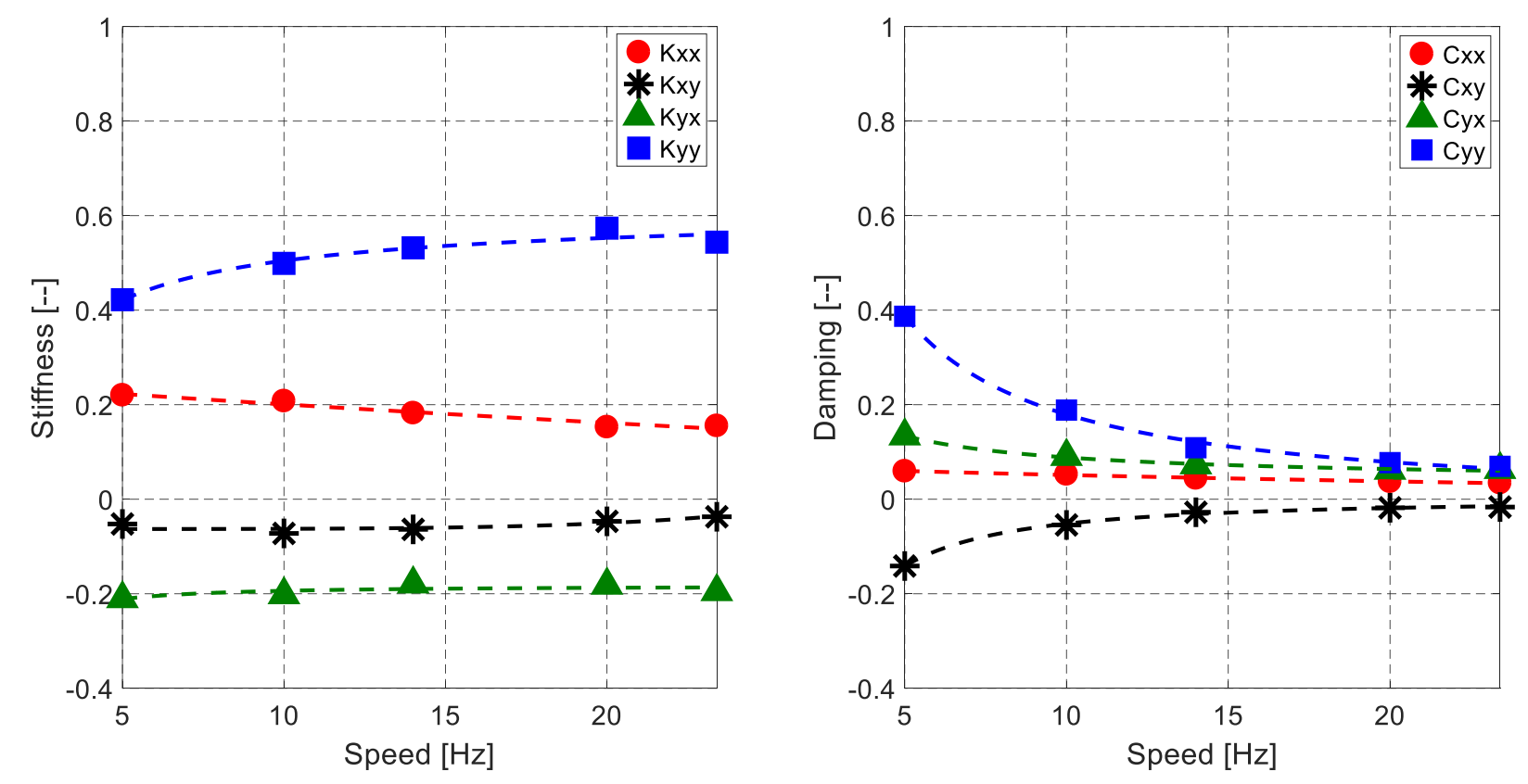

Fig. 10. Dynamic coefficients vs. rotational speed at a static load of $80 \mathrm{kN}$.

In

Fig. 9

and

Fig. 10

the

cross-terms of the damping coefficients $\left(c_{x y}\right)$ show an abnormal, i.e., behaviour changing sign with 
the increase of the static load and negative value with the increase of the rotational speed, respectively. The estimation of the damping cross-terms resulted to be critical for this heavy loading condition. Furthermore only the direct terms of the stiffness and damping coefficient are actually used in the design phase of the system, mainly for issues concerning the stability of the bearingsystem. The abnormal sign of the damping cross-terms can be due to several technical issues of the system layout and setup such as the positon of the load cells, the presence of internal resonances and the setting (amplitude and frequency) of the excitation forces.

\subsection{Static position}

The journal centre position was obtained by averaging the values of the four proximity sensors mounted on the bearing housing at the DE and NDE sides $X_{\text {shaft }}=\left(X_{\mathrm{NDE}}+\mathrm{X}_{\mathrm{DE}}\right) / 2$ and $\mathrm{Y}_{\text {shaft }}=\left(\mathrm{Y}_{\mathrm{NDE}}+\mathrm{Y}_{\mathrm{DE}}\right) / 2$. This averaged position was compared with the value obtained from the two proximity probes installed in the centre of the bearing ring $\left(\mathrm{X}_{C}\right.$ and $\left.\mathrm{Y}_{C}\right)$. Besides, the average of six probes $\mathrm{X}_{\text {avg }}=\left(\mathrm{X}_{\text {shaft }}+\mathrm{X}_{C}\right) / 2$ and $\mathrm{Y}_{\text {avg }}=\left(\mathrm{Y}_{\text {shaft }}+\mathrm{Y}_{C}\right) / 2$ are plotted as well.

Theoretically, the difference is only given by the deformation of the system (bearing housing and shaft). In particular, the proximity probes $\mathrm{X}_{C}$ and $\mathrm{Y}_{C}$ are placed in the bearing ring, where no deformation can occur. NDE and DE probes are placed on the bearing housing; therefore, backlashes or deformation can occur.

The comparison between the shaft centre position obtained with the proximity probes in the bearing ring and with the proximity probes in the housing support is plotted in

\begin{tabular}{|c|c|c|c|c|c|c|c|}
\hline Ref462155791 & $\mathrm{h}$ & Fig. 11 & $(66$ & $\mathrm{rpm}$ & up & to & 50 \\
\hline Ref462155798 & $\mathrm{h}$ & Fig. 12 & $(66$ & $\mathrm{rpm}$ & to & 350 & $\mathrm{kN})$ \\
\hline
\end{tabular}


$\mathrm{EF} \quad$ Ref462155805 $\mathrm{lh}$ Fig. $13 \quad(300 \mathrm{rpm} \quad$ up to $50 \mathrm{kN})$. These figures reveal that for the low load (up to $50 \mathrm{kN}$ ) the shaft centre position obtained with the two different sets of sensors is quite similar. By increasing the load Fig. 12 at $66 \mathrm{rpm}, 350 \mathrm{kN}$ ), a large difference can be detected, probably because of the deformation of the bearing housing or the bending of the shaft.

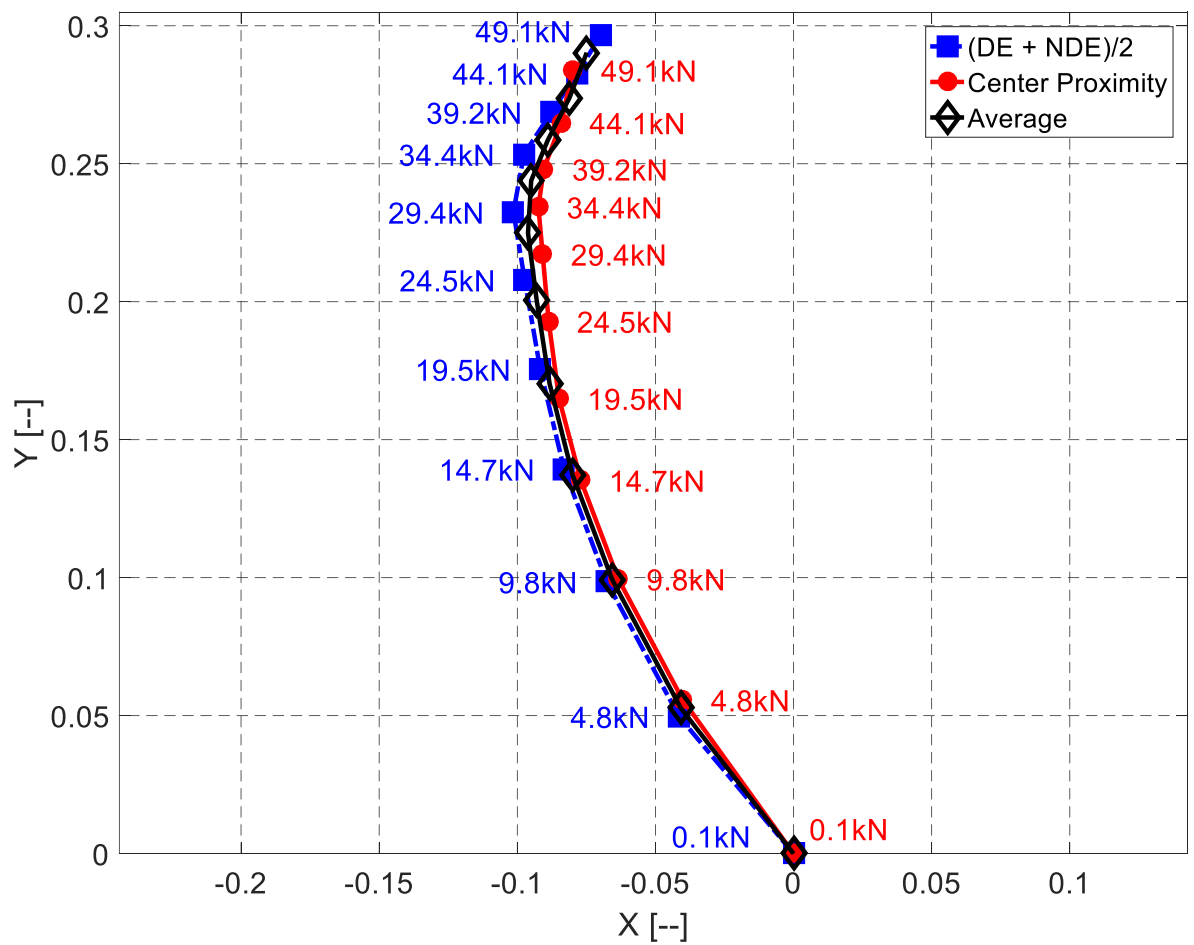

Fig. 11. Static position of shaft vs. static load at a speed of $66 \mathrm{rpm}$. Static load increases up to $50 \mathrm{kN}$. 


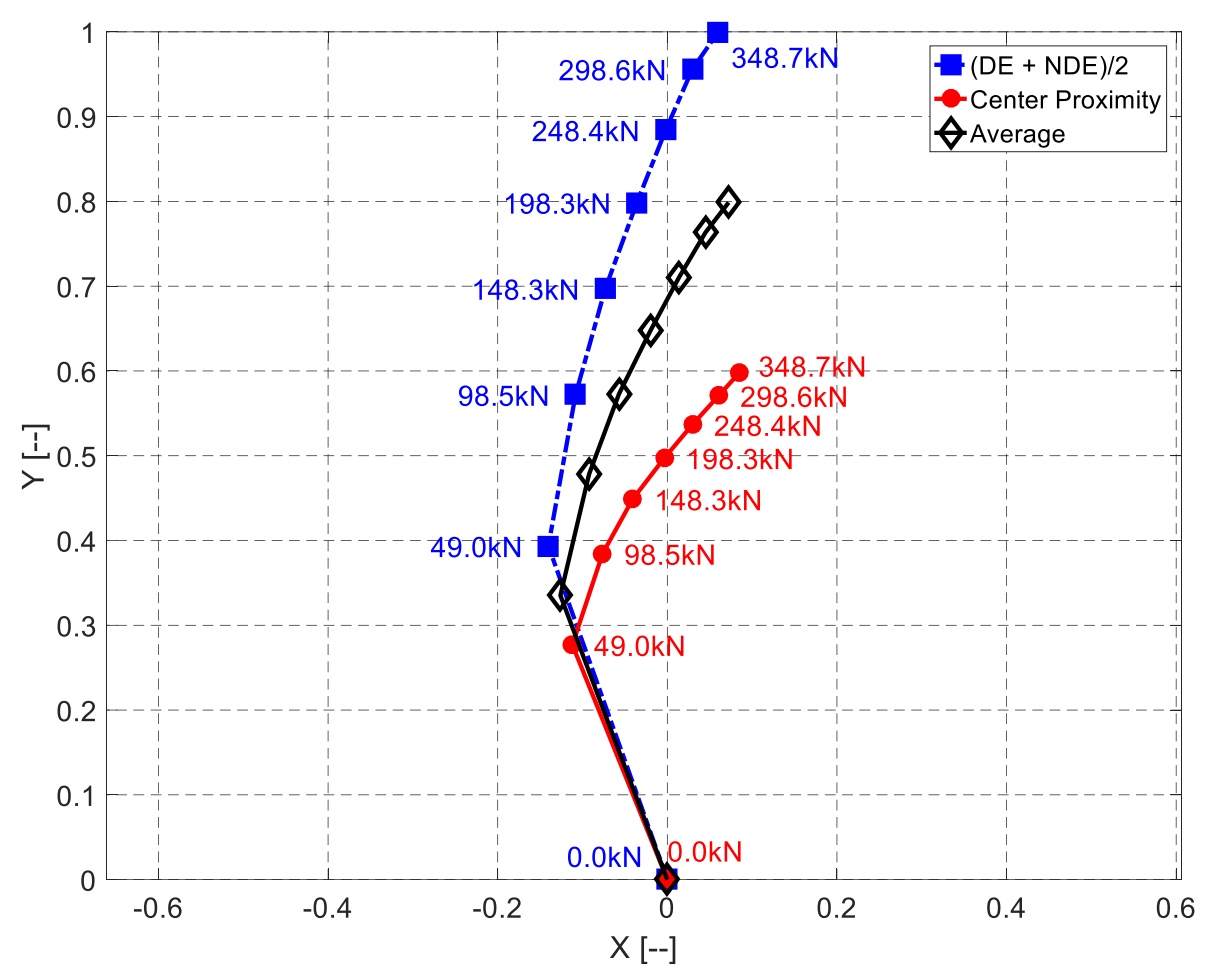

Fig. 12. Static position of shaft vs. static load at a speed of $66 \mathrm{rpm}$. Static load increases up to $350 \mathrm{kN}$.

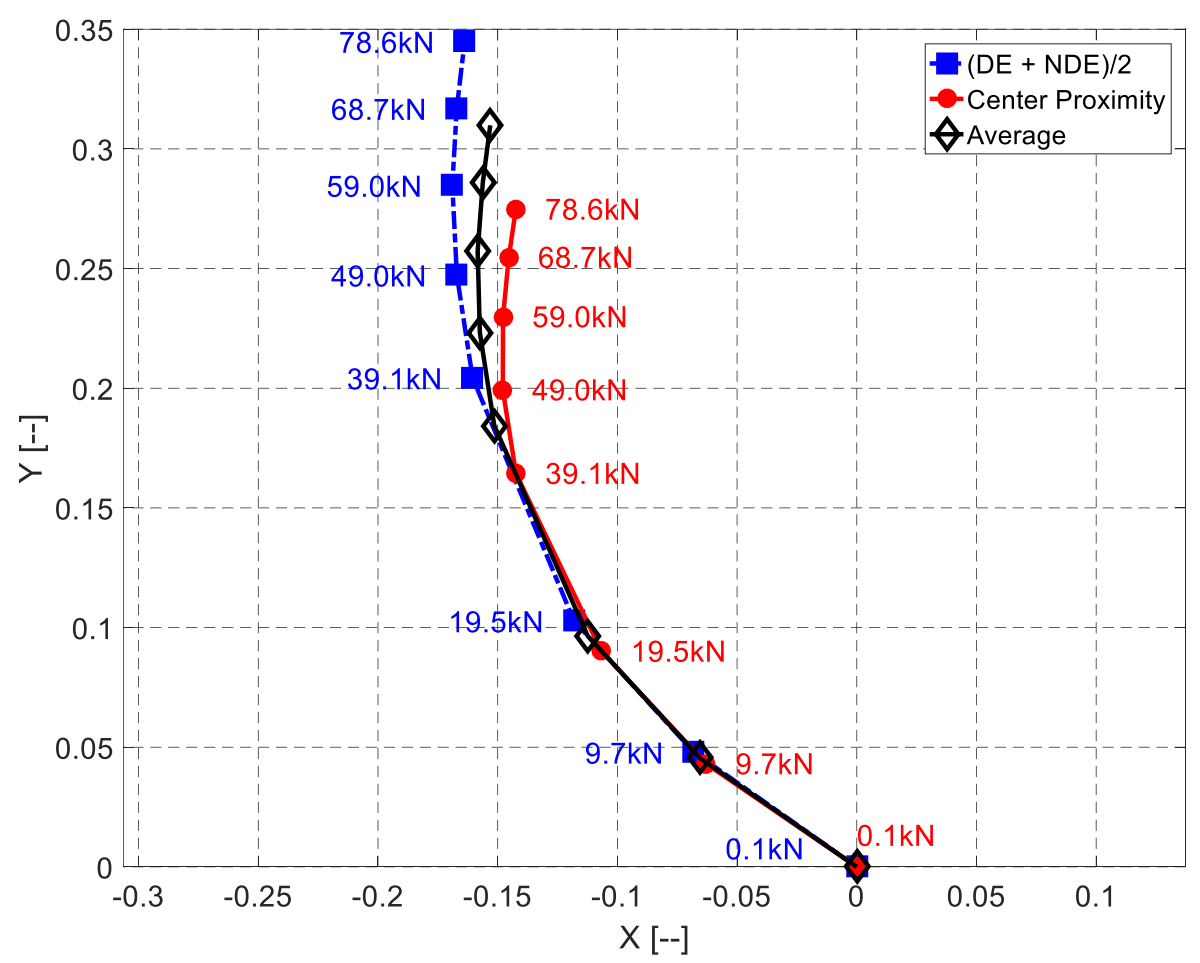

Fig. 13. Static position of shaft vs. static load at a speed of $300 \mathrm{rpm}$. Static load increases up to $80 \mathrm{kN}$. 


\subsection{Temperature distribution}

The temperature distributions in the mid-plane measured by the temperature probes on the external surface of the bearing (approximately at a radial distance of $5 \mathrm{~mm}$ from the bearing surface) are shown in Fig. 14 at the rotational speed of $66 \mathrm{rpm}$. The results are displayed for several values of the static loads and by considering the angular position of the temperature probes (NDE view). As the static load increases, the temperature in the loaded part of the bearing tends to increase because of the increase of the shear stresses, which encourages the growth of heat generation close to the region of minimum oil-film thickness. For all tests, the temperature increases from position $\mathrm{T} 1\left(0^{\circ}\right)$ reaching its higher value at $112.5^{\circ}$ (corresponding to temperature sensor T6) accordingly to the anticlockwise direction of the shaft. This position also corresponds to the position of the maximum pressure and minimum oil-film thickness. After this position the heat generated by the shear stresses decreases and the temperature decrease in the bearing ring due to the heat exchange with the surrounding.

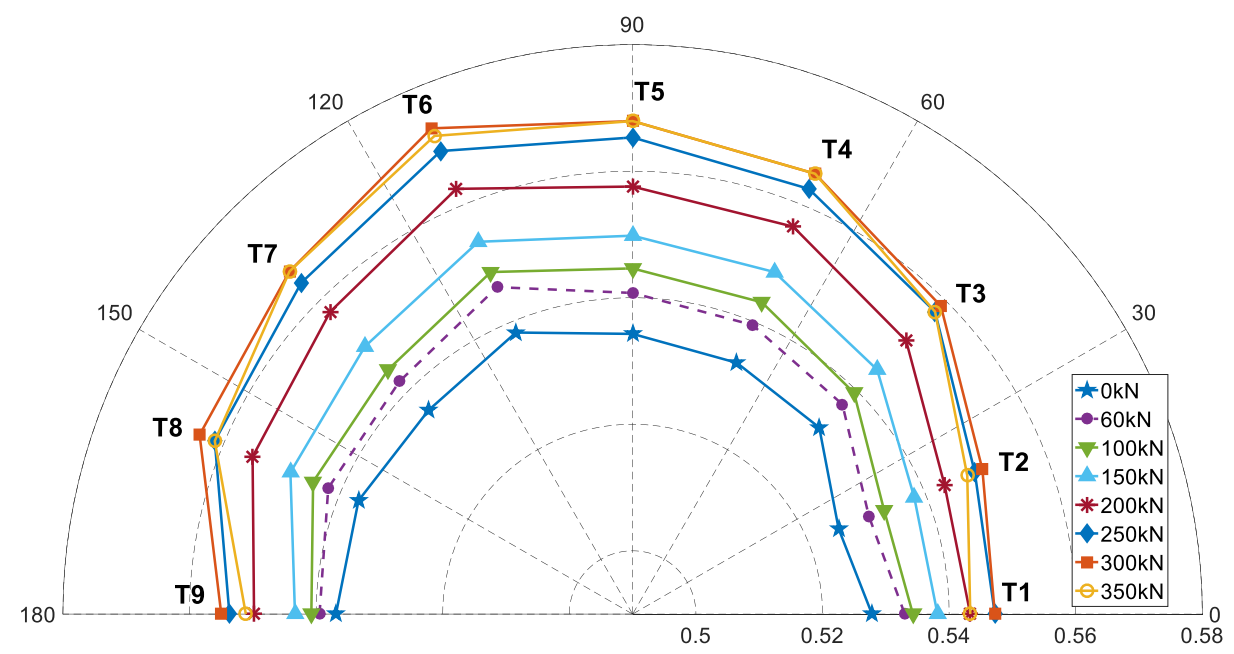

Fig. 14. Bearing temperature vs. static load at a speed of $66 \mathrm{rpm}$ - from the NDE view.

Furthermore, by using the temperature profile at $0 \mathrm{kN}$ as reference and comparing it with the remaining profiles, it is possible to highlight the increase in the bearing temperature when the applied static load in the vertical direction increases up to $350 \mathrm{kN}$. As can be seen in 
REF_Ref469931658 Vh Fig. 15, the increase in the bearing temperature as a function of static load is very small, with a maximum value of about $2.7{ }^{\circ} \mathrm{C}$ (at $\mathrm{T} 6$ position) when the applied static load increases from $0 \mathrm{kN}$ to $300 \mathrm{kN}$. This is mainly due to the low value of the rotational speed $(66 \mathrm{rpm})$.

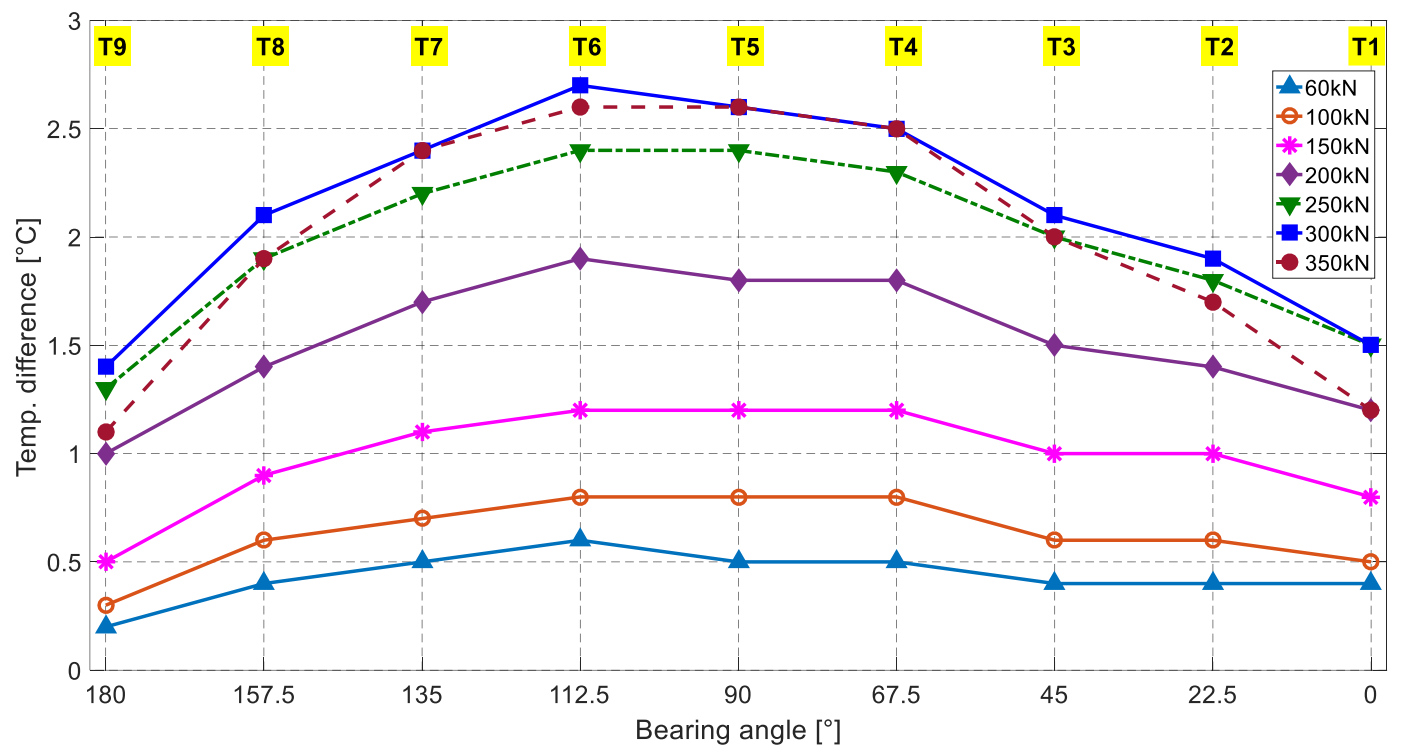

Fig. 15. Temperature difference vs. bearing angle at a speed of $66 \mathrm{rpm}-$ from the NDE view

Similar bearing temperature profiles are shown in Fig. 16 when the shaft speed increases from $5 \mathrm{~Hz}$ to $23.4 \mathrm{~Hz}$. In general, the rising of the rotational speed globally increases the temperature in the bearing. This is because of the growth in the shear rate combined with the rising velocity gradients across the oil- 
film

thickness

[22].

It

can

be

seen

from

Fig. 16

that

the

bearing temperature increases at a rate much greater than that of the previous case (increasing static load). As shaft speed increases from $5 \mathrm{~Hz}$ to $23.4 \mathrm{~Hz}$, the maximum bearing temperature increases approximately 1.5 times.

Note that there is a temperature reduction at the $\mathrm{T} 9$ position. This is due to the presence of the oil inlet hole close to the T9 position. The cold oil $\left(40^{\circ} \mathrm{C}\right)$ is feed at about 3.5 bar and is able to lower the temperature around this area.

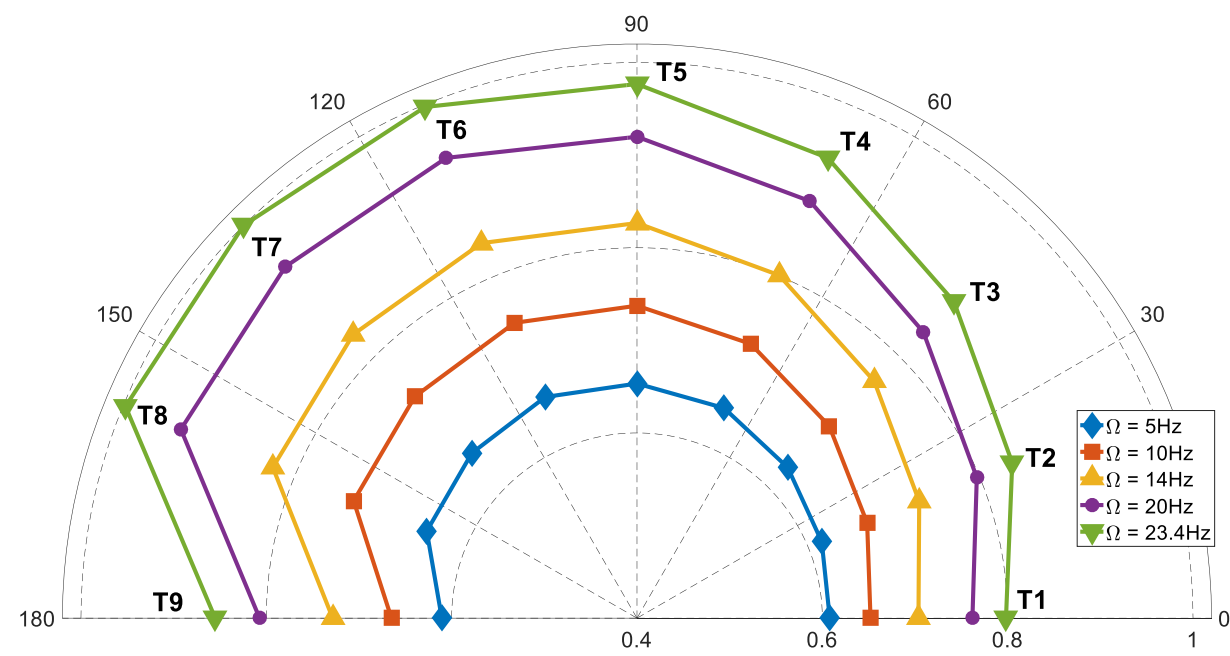

Fig. 16. Bearing temperature vs. rotational speed at a static load of $80 \mathrm{kN}$ - from the NDE view.

Conversely with the temperature increasing as a function of static load, the bearing temperature variation strongly depends on the rotational speed, as shown in 
Fig. 17 (the test of $5 \mathrm{~Hz}$ is used as a reference one). For instance, at the $\mathrm{T} 8$ position, the bearing temperature increases approximately $27^{\circ} \mathrm{C}$ when the rotational speed increases from $5 \mathrm{~Hz}$ to $23.4 \mathrm{~Hz}$.

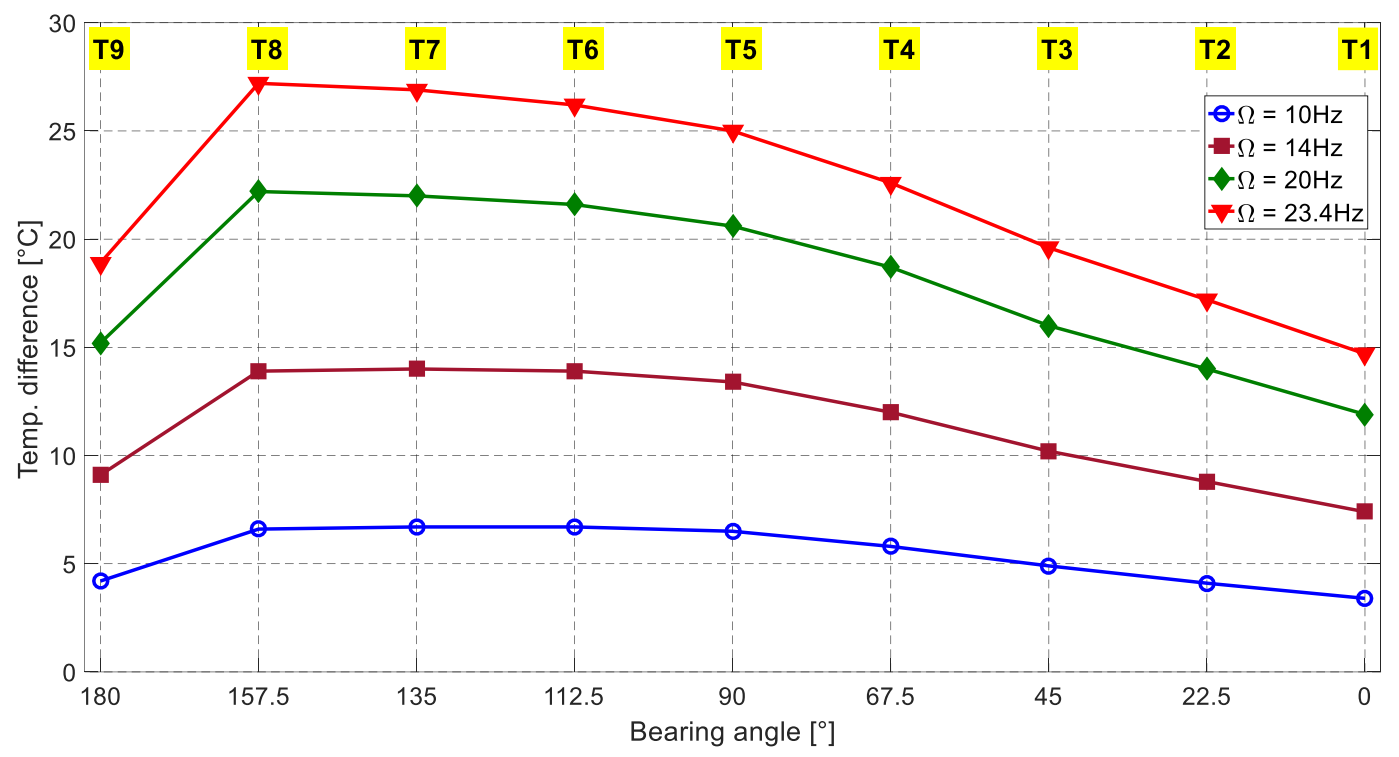

Fig. 17. Temperature difference vs. bearing angle at a static load of $80 \mathrm{kN}$ - from the NDE view

Note that the oil outlet temperature $\left(T_{\text {out }}\right)$ seems to be independent with the applied static load but it strongly depends on the rotational speed, as shown in Fig. 18. As shaft speed increases from $5 \mathrm{~Hz}$ to $23.4 \mathrm{~Hz}$, the value of $T_{\text {out }}$ increases about $50 \%$ and reaches at approximately $81 \%$ of the maximum bearing temperature. 

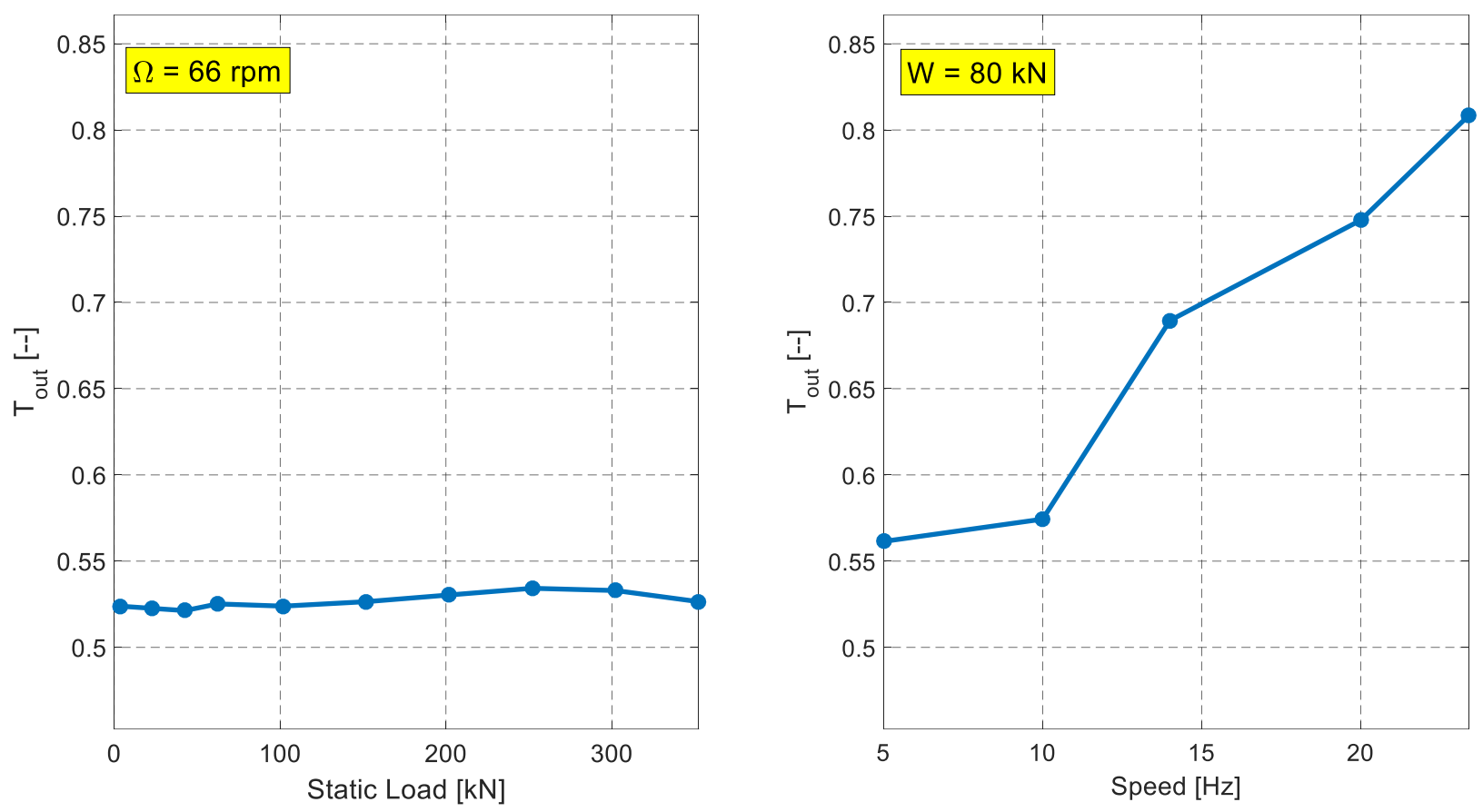

Fig. 18. Influence of the operating conditions: (left) static load and (right) rotational speed on oil outlet temperature.

\subsection{Pressure distribution}

The pressure distribution measured by the rotating pressure probe in the centre of the bearing is shown

in

pressure profiles
Fig. 19

$$
\text { The }
$$

in

$\mathrm{Fi}$ g. 19 are obtained by synchronous averaging of the pressure signal over several revolutions. In Fig. 19, all the tests show the same value (equal to 3-4 bar, that is, the oil feed pressure) in the lower part of the bearing because of the presence of a circumferential groove. 
Fig. 19

shows that the pressure in the loaded part increases with the increase of the applied static load from $0.1 \mathrm{kN}$ to $49.1 \mathrm{kN}$. The maximum value of the pressure is measured at approximately $105^{\circ}$, whereas the decrease of pressure occurs from $150^{\circ}$ to $180^{\circ}$ in the cavitation zone.

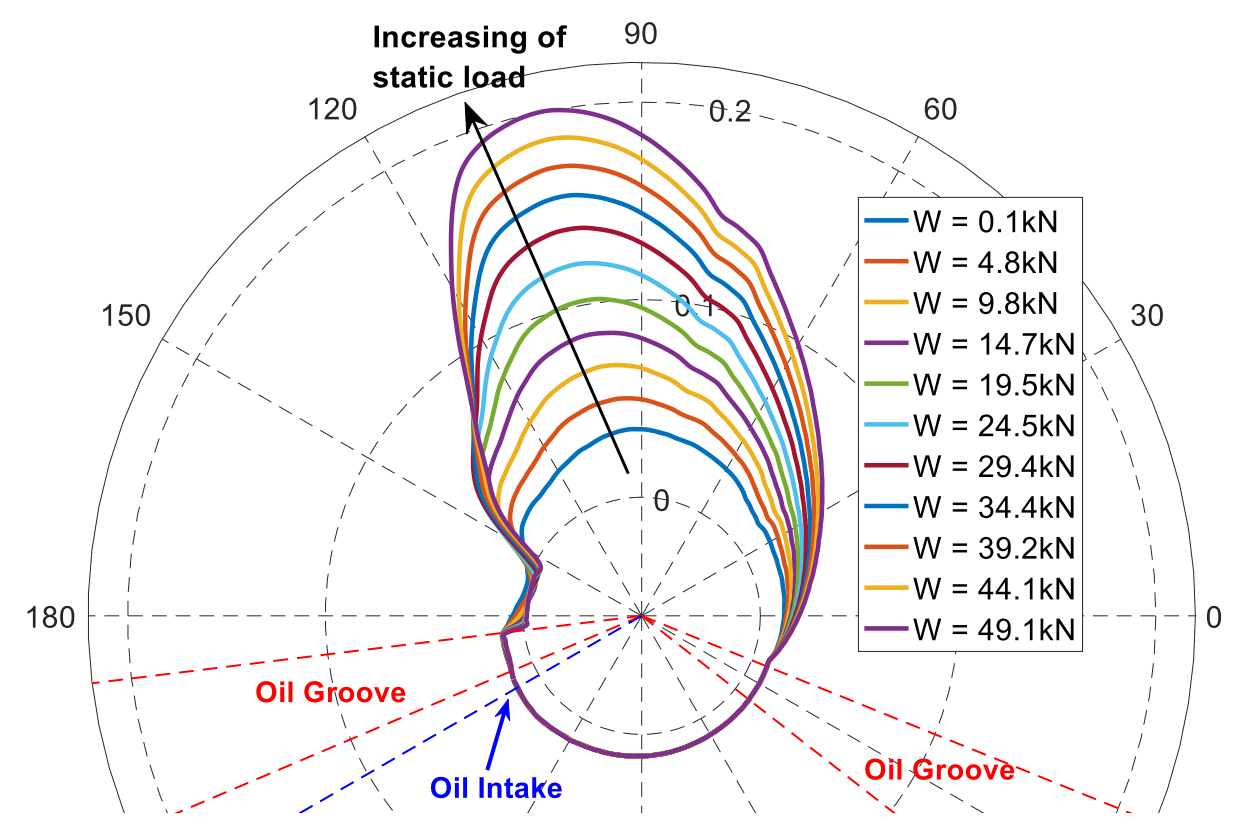

Fig. 19. Pressure distribution vs. static load at a speed of $66 \mathrm{rpm}$. Static load increases up to 50kN.

Fig. 20 shows the bearing's pressure distributions when the applied static load increases from $0 \mathrm{kN}$ to $350 \mathrm{kN}$ in steps of $50 \mathrm{kN}$ at the low rotational speed of $66 \mathrm{rpm}$. For the two last tests, $300 \mathrm{kN}$ and $350 \mathrm{kN}$, the pressure distributions are found to be quite similar, probably because of a thermal drift of the sensor. 
The presence of the hole of the fixed pressure probe in the loaded part of the bearing was detected as a disturbance by the rotating pressure probe (the black points in f462155280 ih $\quad$ Fig. 20). The readers should refer F__Ref456367833 Vh Fig. 3a for the position of the fixed pressure probe.

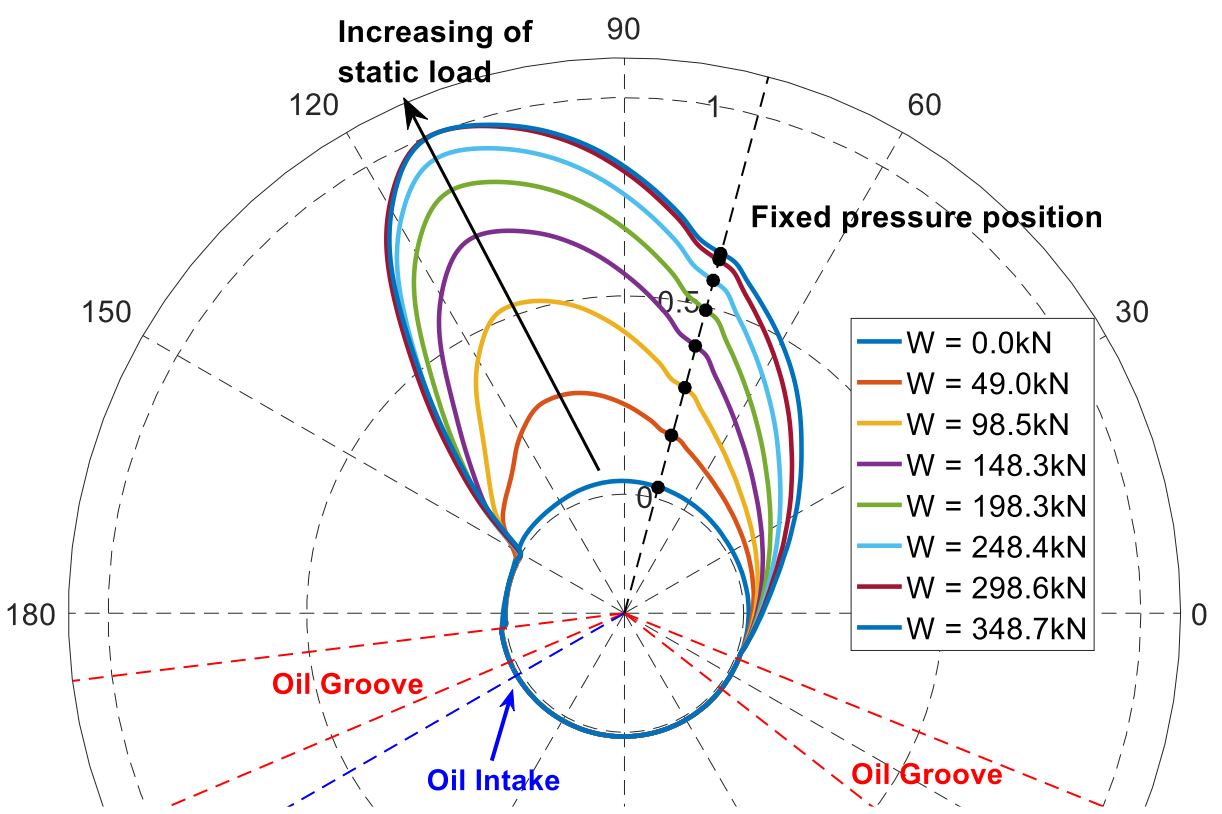

Fig. 20. Pressure distribution vs. static load at a speed of $66 \mathrm{rpm}$. Static load increases up to $350 \mathrm{kN}$. 
bearing's pressure distributions for the constant static load of $80 \mathrm{kN}$ for different rotational speeds. The value and location of the maximum pressure are found to not be affected by the rotational speed. The maximum pressure is detected at approximately $110^{\circ}$. In comparison with the low speed tests, a drop of the pressure occurs from $170^{\circ}$ to $185^{\circ}$.

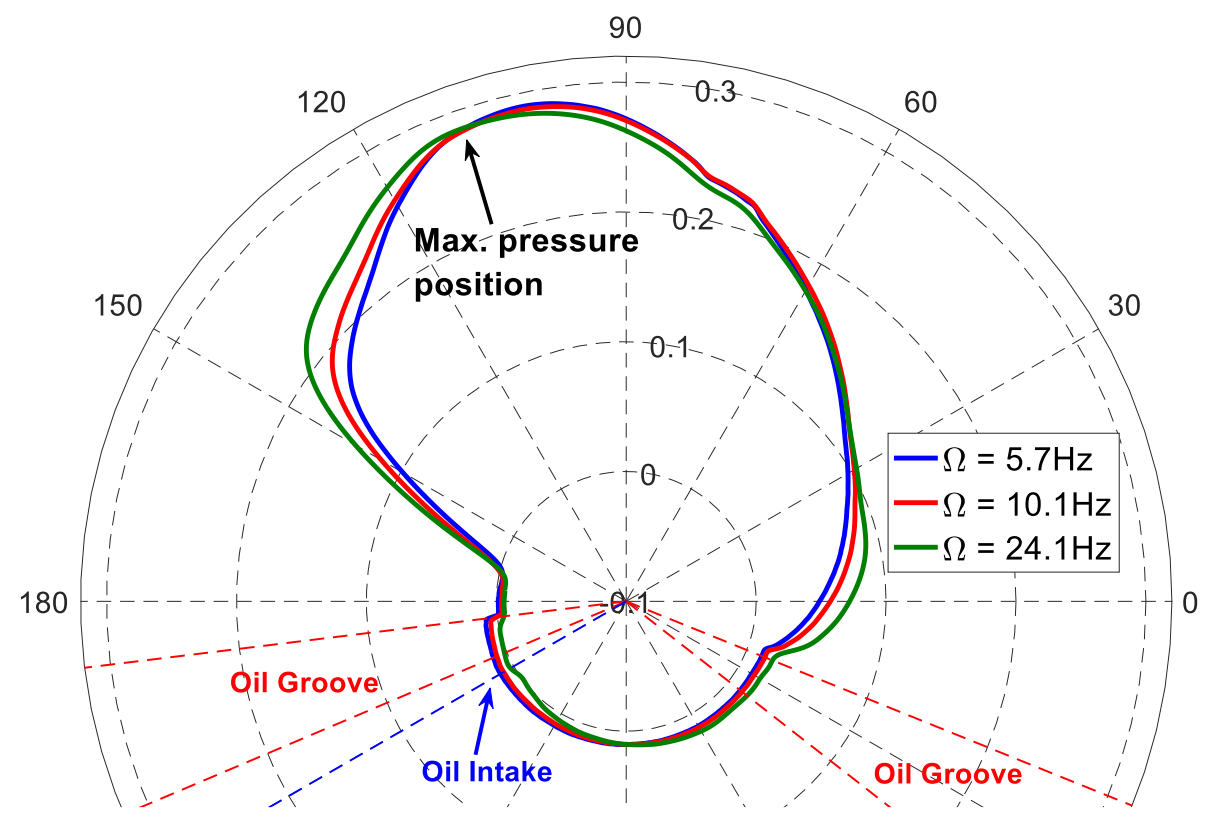

Fig. 21. Pressure distribution vs. rotational speed at a constant static load of $80 \mathrm{kN}$.

\subsection{Oil-film thickness}

The oil-film thickness measured by the rotating proximity probe close to the NDE edge of the bearing is shown in

Fig. 22 for a constant rotational speed of $66 \mathrm{rpm}$ and for several values of the static load. Note that the two discontinuities on the profile of the oil-film thickness are due to the presence of the two axial grooves. 
Fig. 22

shows

that

as

the

static load increases, the film thickness profiles tend to move down and shift to the left because of the different bearing's static position with regard to the journal for different loads. In addition, the shapes of all the film thickness profiles are found to be not exactly similar to circles. This observation is probably owing to the original deformation of the bearing after the installation in the bearing ring (see Fig. 2), to the deformation of the bearing system due to the applied load and to the thermal effect of the not uniform temperature distribution.

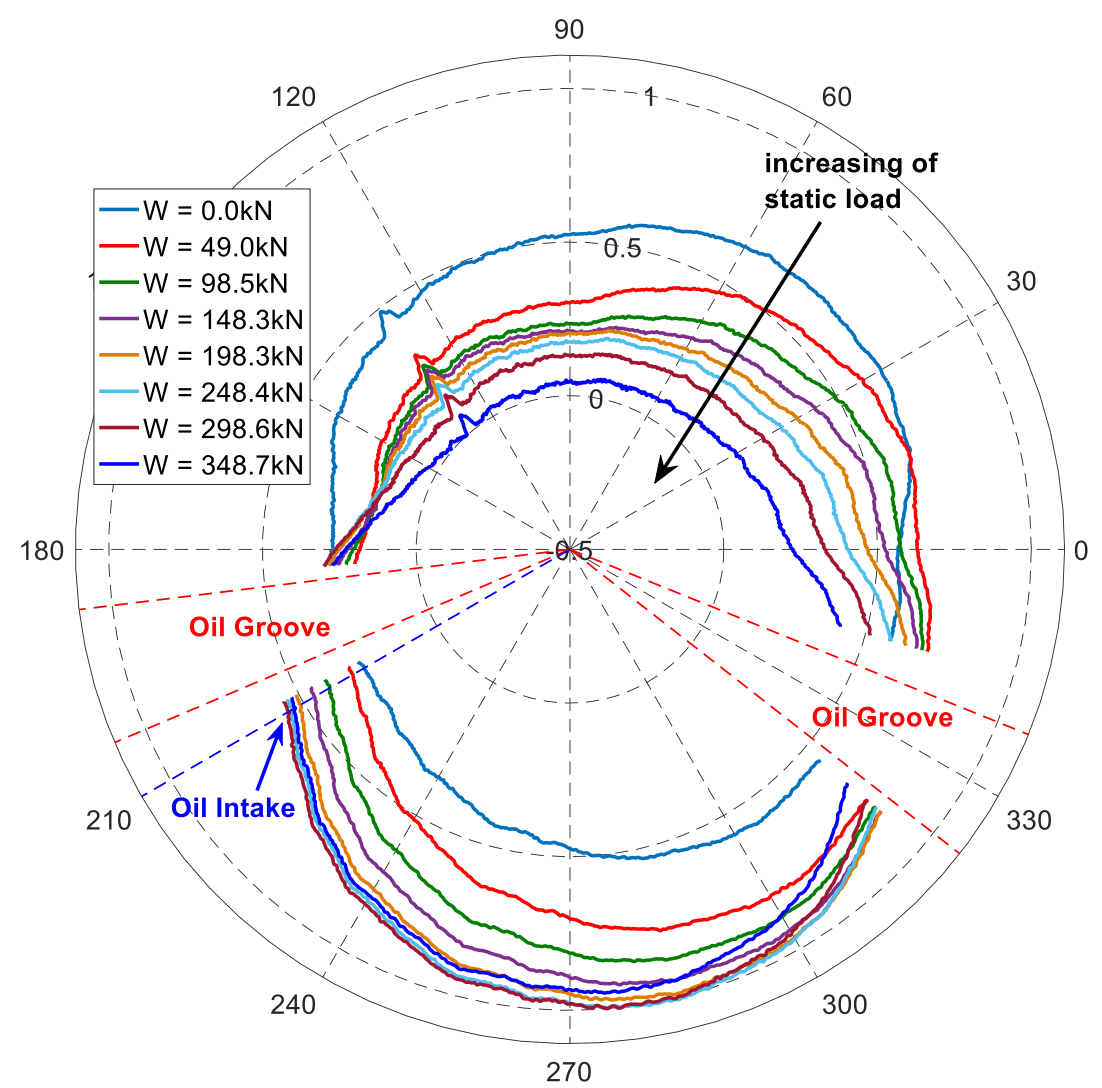

Fig. 22. Oil-film thickness vs. static load at a speed of $66 \mathrm{rpm}$.

Furthermore, by using the profile at $0 \mathrm{kN}$ as reference and comparing it with the remaining profiles, it is possible to identify the deformation of the bearing as a function of static load. For the sake of brevity, the evaluation of bearing deformation is conducted with three tests with static load of $49.0 \mathrm{kN}, 148.3 \mathrm{kN}$, and $248.4 \mathrm{kN}$. 
Fig. 23

shows

the

normalized oil-film thickness of three tests measured by the rotating proximity probe in the shaft reference system. Because of different static positions of the bearing with regard to the shaft at different static loads, it is possible to add the bearing's static position to the corresponding oil-film profiles to evaluate the difference between each thickness profile. However, the static positions of the bearing obtained from the centre proximity probes $\left(\mathrm{X}_{\mathrm{C}}, \mathrm{Y}_{\mathrm{C}}\right)$ show a disagreement with those of proximity probes located on the bearing housing at the DE and NDE sides at larger static loads (see Fig. 12).

Therefore, the

static

positions of the bearing were evaluated by fitting the film thickness profiles with the reference profile. Note that the fitting procedure is only applied to the thickness profiles on the unloaded part of the bearing (from $210^{\circ}$ to $315^{\circ}$ ) at which no bearing deformations are expected because of the negligible value of the pressure.

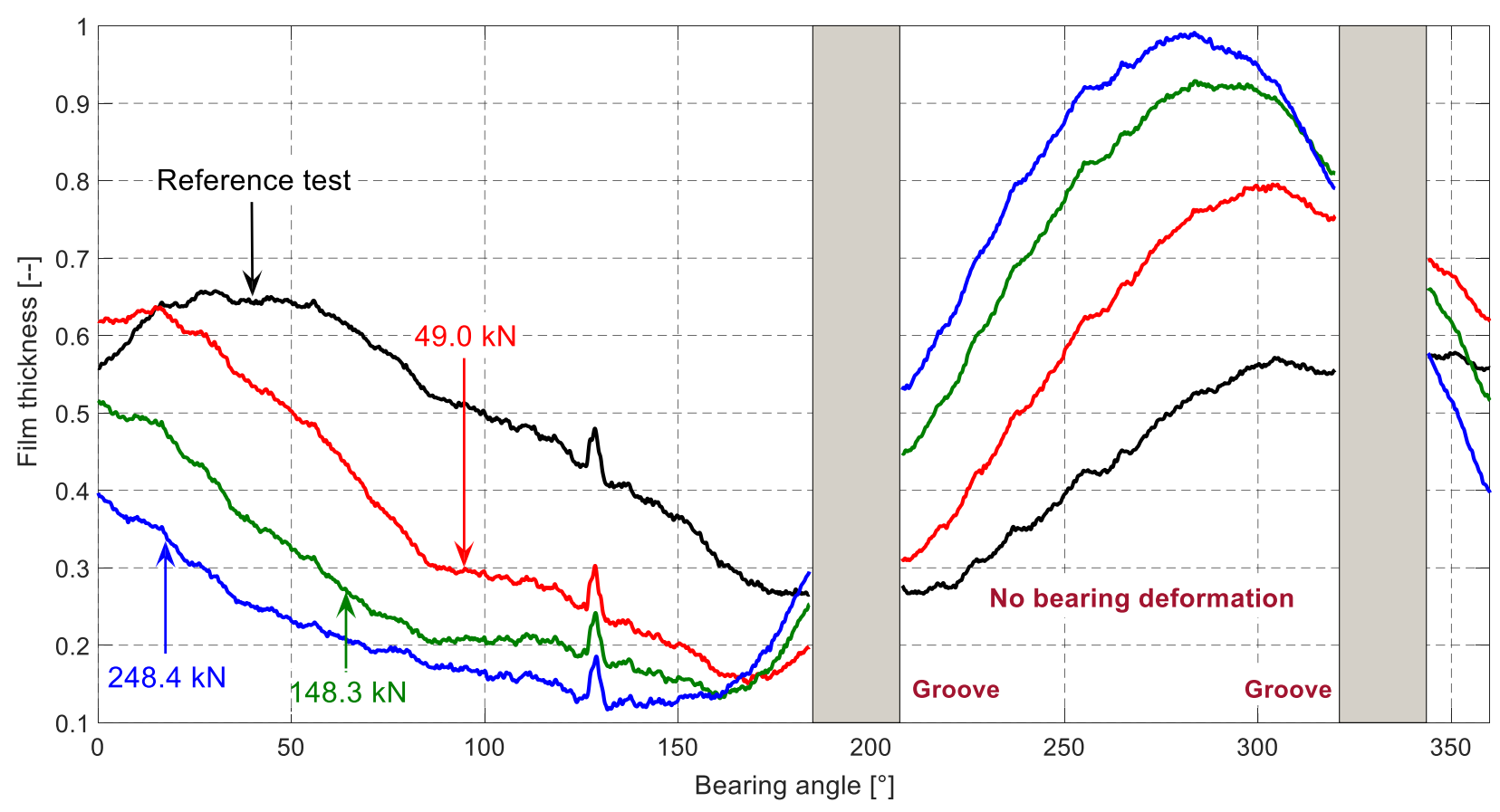

Fig. 23. The oil-film thickness vs. bearing angle of three tests compared to the reference test at $66 \mathrm{rpm}$. 
In particular, the kinematic equations of the bearing profile in the shaft reference system are given by:

$$
\left\{\begin{array}{l}
\left(R_{s}+h\right) \cos \theta=x_{b}+R_{b} \cos \beta \\
\left(R_{s}+h\right) \sin \theta=y_{b}+R_{b} \sin \beta
\end{array}\right.
$$

where:

- $\quad R_{s}=80.000 \mathrm{~mm}$ is the given shaft radius

- $\quad R_{b}$ is the radius of the bearing profile (in the bearing ref. sys.)

- $\quad \theta$ is the angular position of the measured oil-film thickness (in the shaft ref. sys.)

- $\quad \beta$ is the angular position of the bearing profile (in the bearing ref. sys.)

- $x_{b}, y_{b}$ are the coordinates of the centre position of the bearing profile (in the shaft ref. sys.)

- $\quad h$ is the measured oil-film thickness (in the shaft ref. sys.).

The bearing profile (coordinates $R_{b}$ and $\beta$ ) is then obtained from eq. $463349214 \mathrm{lh}(5)$, for a given centre position of the bearing $x_{b}, y_{b}$.

Fig. 24

presents

the fitting procedure for the test of $248.4 \mathrm{kN}$. The centre position of the bearing $x_{b}, y_{b}$, can be estimated through the minimization of the objective function:

$$
\vartheta=\sum\left(R_{b, \text { profile }}-R_{b, \text { ref }}\right)^{2}
$$

where $R_{b, r e f}$ is the coordinate of the reference bearing profile, and $R_{b, p r o f i l e}$ is the coordinate of the real bearing profile that must be fitted. 
When the centre position of the fitted bearing profile is identified, the new bearing's profile can be obtained in the same reference system. The bearing deformation of each test can be calculated by subtracting the reference profile from this new profile. In this manner, the original and irregular shape of the bearing can also be removed.

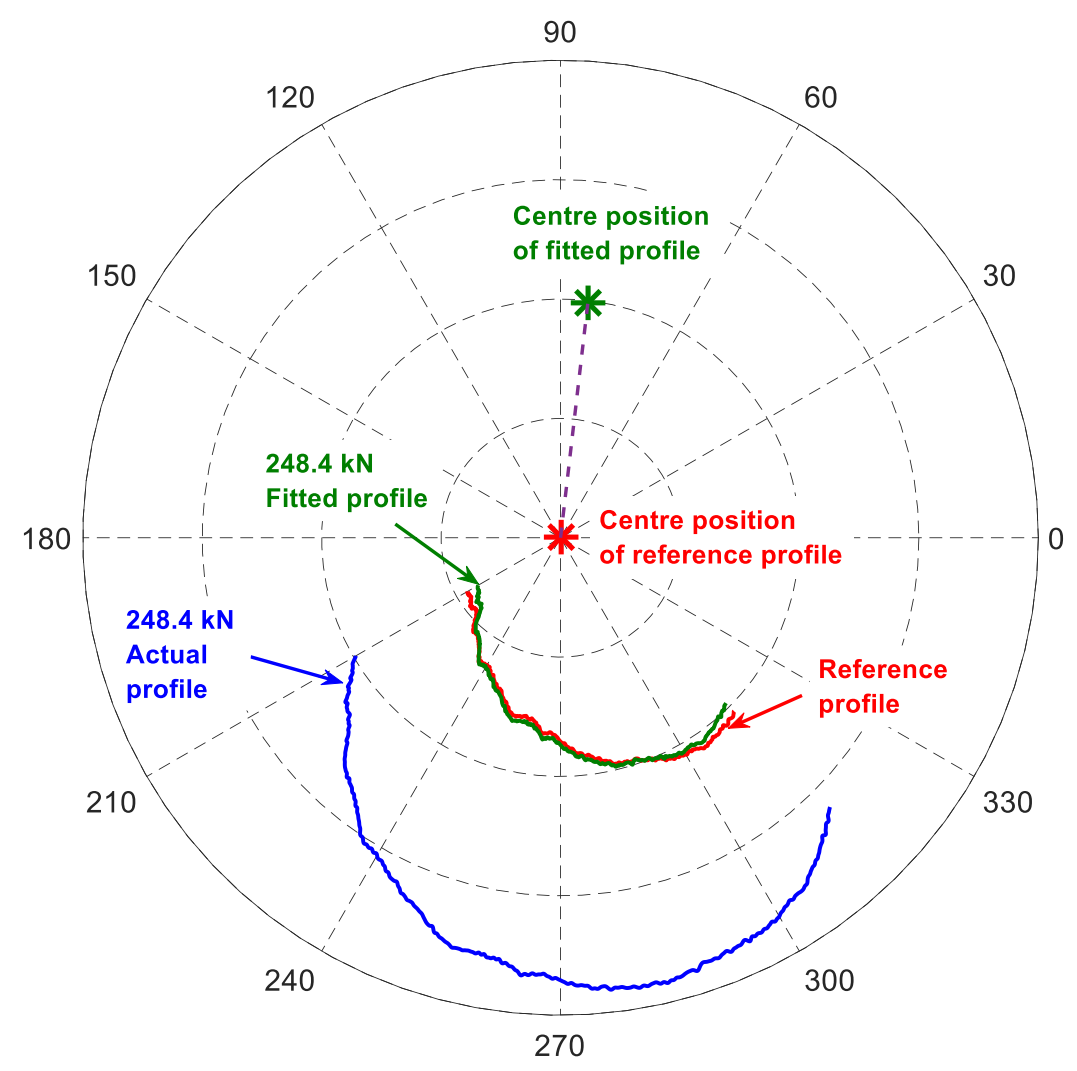

Fig. 24. Reference, actual and fitted profile for bearing deformation evaluation.

The bearing deformations of three tests are shown in Fig. 25, where the tests with large static load are performed in a short time. Hence, in this case, thermal expansion of the rotating shaft and the bearing housing can be neglected. On one hand, it is possible to detect that the bearing deformation increases with the 
increase of the static load and mainly occurs in the vertical direction because of the applied static load direction. On the other hand, "negative" deformation in the horizontal direction occurs on both sides of the bearing.

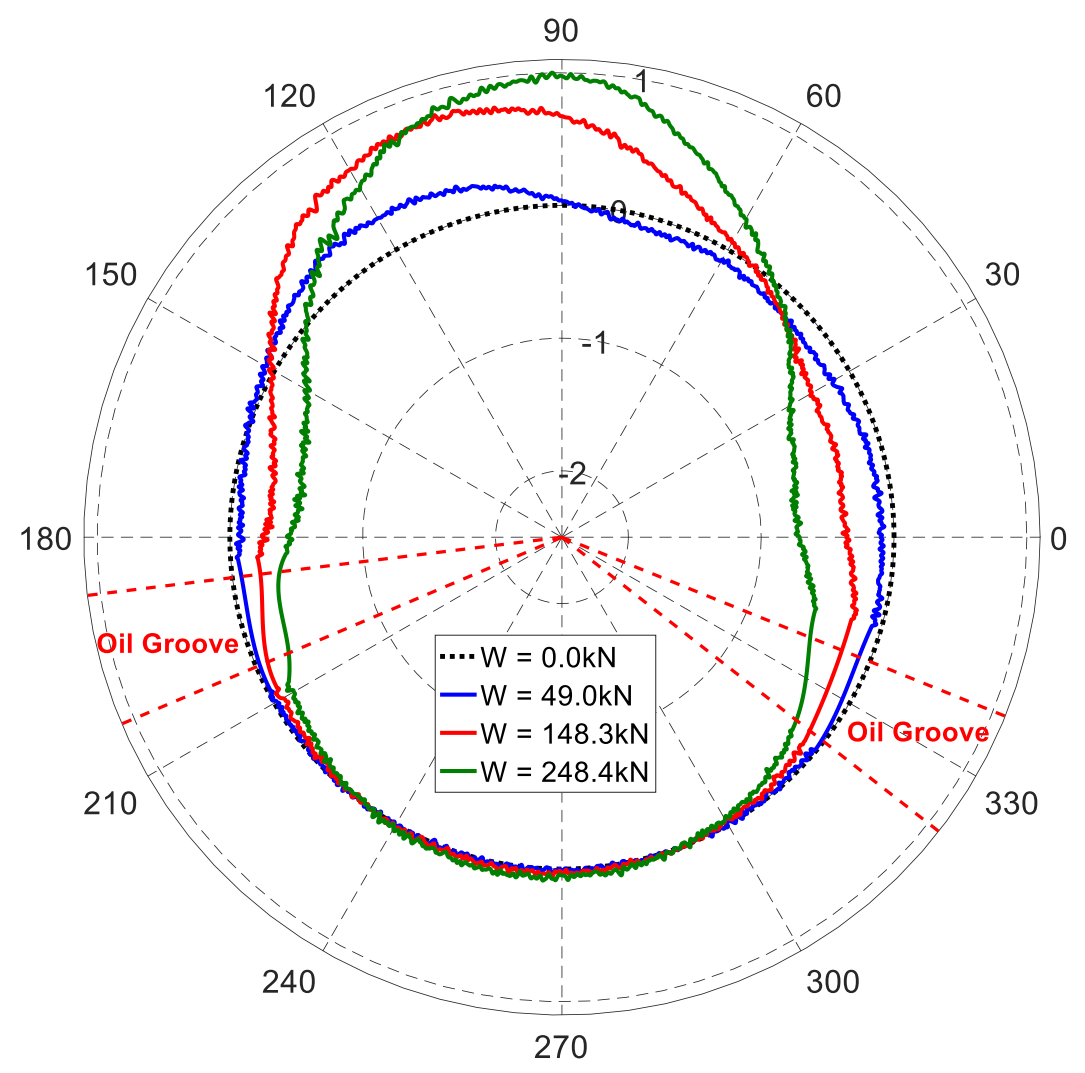

Fig. 25. The bearing deformations for three static loads at $66 \mathrm{rpm}$.

Note that the bearing's static position can be identified from the oil-film thickness profile by $\begin{array}{lllll}\text { using the } & \text { same } & \text { fitting } & \text { Fig. } 26\end{array}$ shows the shaft centre position obtained from the following: proximity probes in the bearing ring (red), inside of the bearing housing (blue), the average of six probes (pink) and the fitting procedure (black). The centre positions obtained by averaging the six probes clearly show a good agreement with those of the fitting procedure, except for at high static loads where a thermal shift of the rotating sensor or a thermal expansion of the shaft probably occurred. 


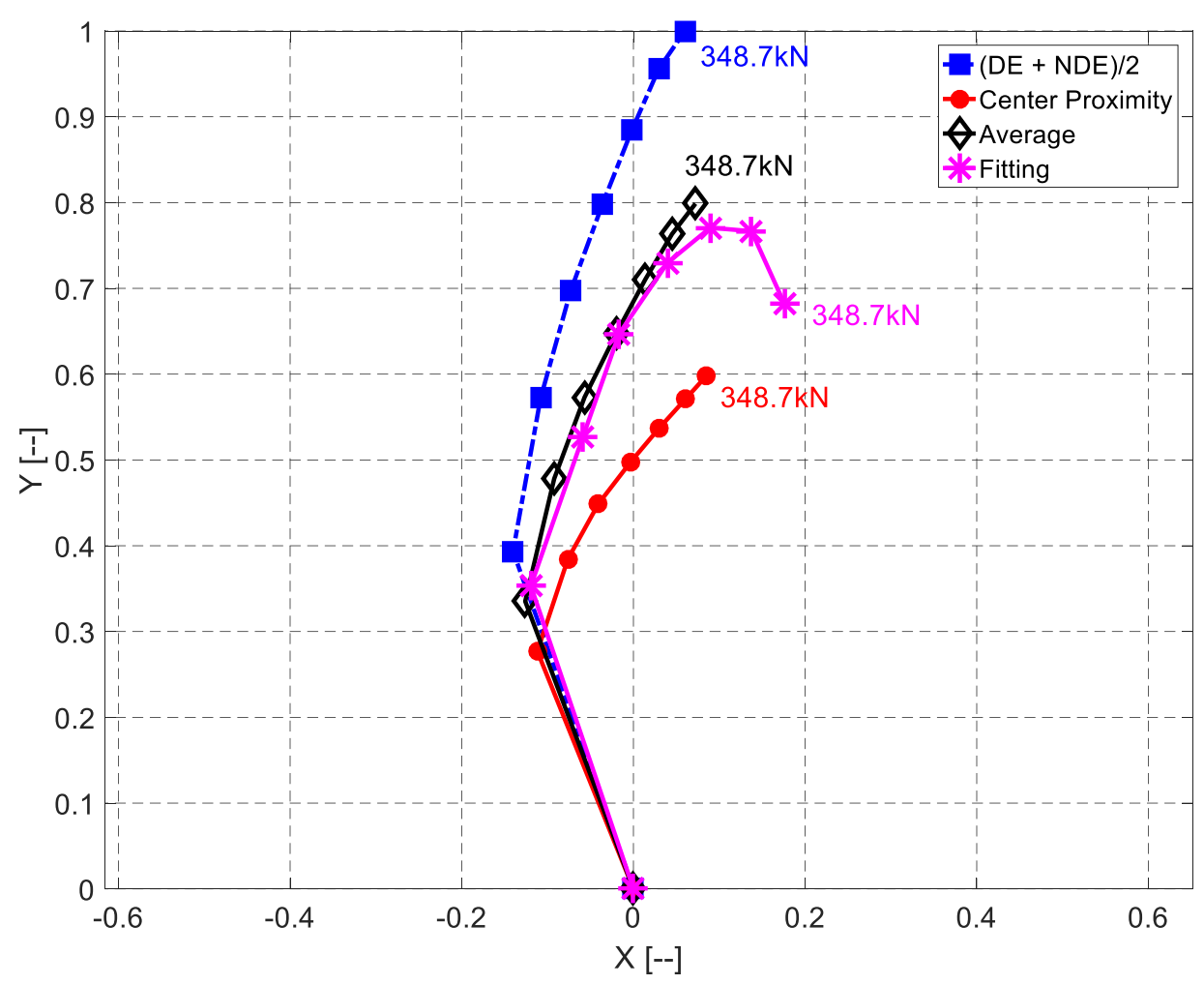

Fig. 26. Comparison of the shaft centre positions obtained from proximity probes on the NDE and DE sides (blue), centre of the bearing (red), average of six probes (pink) and the fitting procedure (black).

Fig. 27

depicts

the

influence of the rotational speed on the film thickness at a constant static load of $80 \mathrm{kN}$. Similar to the previous problem, the first test with a rotational speed of $5.7 \mathrm{~Hz}$ is used as a reference test.

The increase in rotational speed from $5.7 \mathrm{~Hz}$ to $24.1 \mathrm{~Hz}$ was observed to yield a decrease in the film thickness of $5 \%$ and $20 \%$ on average at $10.1 \mathrm{~Hz}$ and $24.1 \mathrm{~Hz}$, respectively. This observation can be explained by the thermal expansion of the shaft, because the shaft temperature is significantly affected by the rotational speed 
[22]. The position of the minimum film thickness is detected at approximately $155^{\circ}$.

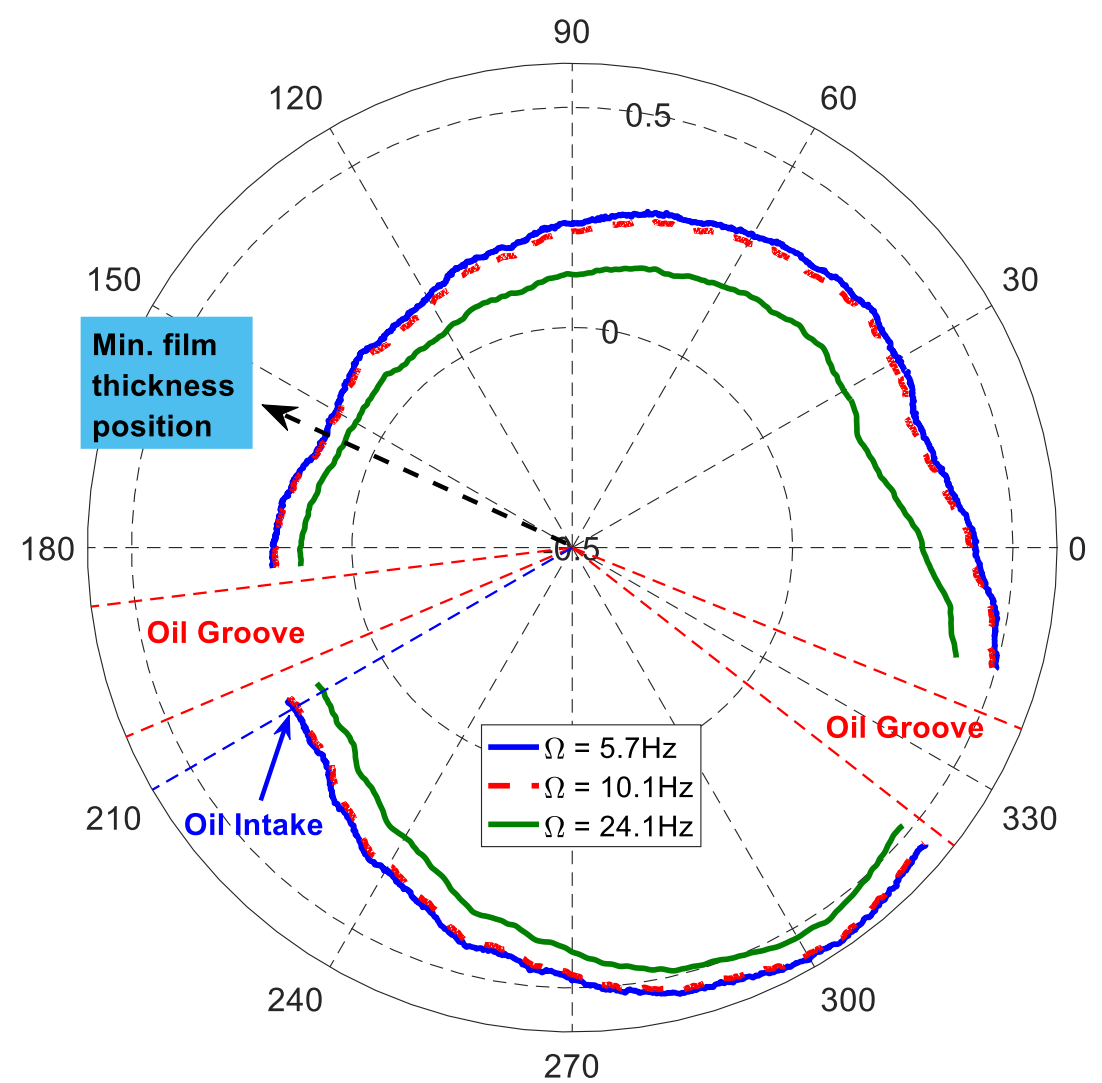

Fig. 27. Oil-film thickness vs. rotational speed at a static load of $80 \mathrm{kN}$.

\section{CONCLUSIONS}

An experimental investigation on the behaviours of a two axial groove journal bearing was conducted for several values of the static load and the rotational speed. The static load ranged from $0 \mathrm{kN}$ to $350 \mathrm{kN}$, and the rotational speed ranged from $66 \mathrm{rpm}$ to $1440 \mathrm{rpm}$. The results for the dynamic coefficients, shaft centre position, temperature profiles, hydrodynamic pressure, oil-film thickness, and bearing deformation were presented and discussed. Some conclusions can be inferred from the experimental results:

1. For the low load (up to $50 \mathrm{kN}$, corresponding to the specific pressure of $2 \mathrm{MPa}$ ), the shaft centre position obtained with the two different position of the sensors is quite similar. By increasing 
the load (up to $350 \mathrm{kN}$, corresponding to the specific pressure of $15 \mathrm{MPa}$ ), a large difference can be detected, probably because of the deformation of the bearing housing or the bending of the shaft.

2. The dynamic direct stiffness coefficients strongly depend on the applied static load and rotational speed, especially the direct stiffness coefficients in the loaded direction, $k_{y y}$. The direct stiffness coefficients increase with the increase of the static load. An opposite trend is found for the direct damping coefficients, i.e., they decrease with the increase of the applied static load or shaft speed.

3. The increase in the load or speed caused the temperature increase in the loaded part of the bearing. At the bearing angle of $112.5^{\circ}$, close to the minimum film thickness position, the maximum temperature occurs.

4. The pressure in the loaded part of the bearing increases with the increase of the applied static load. The maximum pressure position for all tests occurs at approximately $105^{\circ}$. A decrease in the pressure occurs from $150^{\circ}$ to $180^{\circ}$ in the cavitation zone. However, the pressure distribution is quite stable with the shaft speed. The profile of the pressure distribution for tests at low and high speed is quite similar.

5. By increasing the rotational speed, the oil film thickness tends to decreases because of the thermal expansion of the shaft. In addition, the oil-film thickness profiles are not similar to circles. This observation is probably owing to the thermal expansion and the deformation of the system.

6. The bearing deformation can be calculated based on the oil-film thickness. This deformation increases with the increase of the static load and mainly occurs in the loaded part of the bearing. Furthermore, the centre position of the bearing can be identified from the oil-film thickness profile by a fitting procedure.

\section{ACKNOWLEDGMENT}

The present work was undertaken under the project C. RIC. N. 32/14 DANIELI, funded by DANIELI \& C OFFICINE MECCANICHE S.p.A. The work has been carried out at the Department of Mechanical Engineering of Politecnico di Milano (Italy). 


\section{REFERENCES}

[1] Tala-Ighil N, and Fillon M. A numerical investigation of both thermal and texturing surface effects on the journal bearings static characteristics. Tribol Int 2015;90:228-239.

[2] Solghar AA. Three-dimensional hydrodynamic analysis of journal bearings using lattice Boltzmann method. Proc IMechE, Part J: J Engineering Tribology 2016;230:817-826.

[3] Trachsel M, Pittini R, Dual J. Friction and 2D position measurements in small journal bearings. Tribol Int 2016;102:555-560.

[4] Cheng F, Ji W. Velocity-slip model for analysis of the fluid film in the cavitation region of a journal bearing. Tribol Int 2016;97:163-172.

[5] Dousti S, Allaire P, Dimond T, and Cao J. An extended Reynold equation applicable to high reduced Reynolds number operation of journal bearings. Tribol Int 2016;102:182-197.

[6] Kango S, Sharma RK, and Pandey RK. Comparative analysis of textured and grooved hydrodynamic journal bearing. Proc IMechE, Part J: J Engineering Tribology 2014;228:8295.

[7] Mehrjardi M, Rahmatabadi AD, and Meybodi RR. A comparative study of the preload effects on the stability performance of noncircular journal bearings using linear and nonlinear dynamic approaches. Proc IMechE, Part J: J Engineering Tribology 2016;230:797-816.

[8] Illner T, Bartel D, and Deters L. Determination of the transition speed in journal bearings under consideration of bearing deformation. Tribol Int 2015;82:58-67.

[9] Brito FP, Miranda AS, Bouyer J, and Fillon M. Experimental investigation of the influence of supply temperature and supply pressure on the performance of a two-axial groove hydrodynamic journal bearing. J Tribol 2007;129:98-105.

[10] Brito FP, Miranda AS, Clara JCP, Teixeira JC, Costa L, and Fillon M. Thermohydrodynamic modelling of journal bearings under varying load angle and negative groove flow rate. Proc IMechE, Part J: J Engineering Tribology 2014;228:955-973.

[11] Ertas B, Drexel M, Van Dam J, and Hallman D. A general purpose test facility for evaluating gas lubricated journal bearings. J. Eng. Gas Turbines Power 2008;131(2):022502.

[12] Heshmat H, Walowit JA, and Pinkus O. Analysis of Gas-Lubricated Foil Journal Bearings. J Lubrication Tech 1983;105(4):647-655.

[13] Bert CW, and Malik M. Transient Analysis of Gas-Lubricated Journal Bearing Systems by Differential Quadrature. J Tribol 1997;119(1):91-99.

[14] Gao G, Yin Z, Jiang D, and Zhang X. Numerical analysis of plain journal bearing under hydrodynamic lubrication by water. Tribol Int 2014;75:31-38.

[15] Gao G, Yin Z, Jiang D, Zhang X, and Wang Y. Analysis on design parameters of waterlubricated journal bearings under hydrodynamic lubrication. Proc IMechE, Part J: J Engineering Tribology 2016;230:1019-1029.

[16] Zhang X, Yin Z, Gao G, and Li Z. Determination of stiffness coefficients of hydrodynamic water-lubricated plain journal bearings. Tribol Int 2015;85:37-47. 
[17] Zhang X, Yin Z, Jiang D, Gao G, Wang Y, and Wang X. Load carrying capacity of misaligned hydrodynamic water-lubricated plain journal bearings with rigid bush materials. Tribol Int 2016;99:1-13.

[18] Ren T, Feng M. Stability analysis of water-lubricated journal bearings for fuel cell vehicle air compressor. Tribol Int 2016;95:342-348.

[19] Lin Q, Wei Z, Zhang Y, and Wang N. Effects of the slip surface on the tribological performances of high-speed hybrid journal bearings. Proc IMechE, Part J: J Engineering Tribology 2016;230:1149-1156.

[20] Khatri CB, Sharma SC. Influence of textured surface on the performance of non-recessed hybrid journal bearing operating with non-Newtonian lubricant. Tribol Int 2016;95:221-235.

[21] Jain D and Sharma SC. Combined influence of geometric irregularities of journal and turbulence on the performance of four-lobe hybrid journal bearing. Proc IMechE, Part J: J Engineering Tribology 2015;229:1409-1424.

[22] Brito FP, Bouyer J, Fillon M, and Miranda AS. Thermal behavior and performance characteristics of a twin axial groove journal bearing as a function of applied load and rotational speed. $5^{\text {th }}$ International Conference on Mechanics and Materials in Design, 2006.

[23] Wang JK, and Khonsari MM. Effects of oil inlet pressure and inlet position of axially grooved infinitely long journal bearings. Part I: analytical solutions and static performance. Tribol Int 2008;41:119-131.

[24] Wang JK, and Khonsari MM. Effects of oil inlet pressure and inlet position of axially grooved infinitely long journal bearings. Part II: nonlinear instability analysis. Tribol Int 2008;41:132-140.

[25] Gardner WW. Journal bearing operation at low Sommerfeld numbers. ASLE Trans 1976;19(3):187-194.

[26] Ahmad MA, Kasolang S, and Dwyer-Joyce RS. Experimental study on the effects of oil groove location on temperature and pressure profiles in journal bearing lubrication. Tribol Int 2014;74:79-86.

[27] Costa L, Fillon M, Miranda AS, and Claro JCP. An experimental investigation of the effects of groove location and supply pressure on the THD performance of a steadily loaded journal bearing. J Tribol 2000;122:6.

[28] Schiffmann J. Enhanced groove geometry for herringbone grooved journal bearings. J Eng Gas Turbines Power 2013;135(10):102501.

[29] Lu X, Khonsari MM, and Gelinck M. The Stribeck curve: experimental results and theoretical prediction. J Tribol 2006;128:789-794.

[30] Lu X, Khonsari MM. On the lift-off speed in journal bearing. Tribol Lett 2005;20(3):299305.

[31] Allmaier H, Priestner C, Reich FM, Priebsch HH, Novotny-Farkas F. Predicting friction reliably and accurately in journal bearings-extending the EHD simulation model to TEHD. Tribol Int 2013;58:20-28. 
[32] Allmaier H, Priestner C, Sander DE, Reich FM. Friction in automotive engines. Tribology in Engineering 2013:149-184.

[33] Allmaier H, Priestner C, Priebsch HH, Forstner C, Novotny-Farkas F. Predicting friction reliably and accurately in journal bearings-A systematic validation of simulation results with experimental measurements. Tribol Int 2011;44(10):1151-1160.

[34] Sander DE, Allmaier H, Priebsch HH, Reich FM, Witt M, Füllenbach T, Skiadas A, Brouwer L, Schwarze H. Impact of high pressure and shear thinning on journal bearing friction. Tribol Int 2015;81:29-37.

[35] Chatterton S, Pennacchi P, Dang PV, and Vania A. Identification dynamic force coefficients of a five-pad tilting-pad journal bearing. In: Proceedings of 9th International Conference on Rotor Dynamics (IFToMM); 2014, Italy;21:931-941. http://dx.doi.org/10.1007/978-3-31906590-8_76.

[36] Dang PV, Chatterton S, Pennacchi P, and Vania A. Effect of the load direction on nonnominal five-pad tilting-pad journal bearings. Tribol Int 2016;98:197-211. http://dx.doi.org/10.1016/j.triboint.2016.02.028.

[37] Dang PV, Chatterton S, Pennacchi P, Vania A, Cangioli F. Behavior of a tiltingpad journal bearing with different load directions. Paper No. DETC201546598; 2015. 8. http://dx.doi.org/10.1115/DETC2015-46598.

[38] Dang PV, Chatterton S, Pennacchi P, Vania A, Cangioli F. An experimental study of nonlinear oil-film forces in a tilting-pad journal bearing. Paper No. DETC2015-46601. ASME 2015. http://dx.doi.org/10.1115/DETC2015-46601.

[39] Chatterton S, Dang PV, Pennacchi P, Luca AD, and Flumian F. Experimental evidences of a cylindrical journal bearing operating at very low Sommerfeld numbers. In: Proceedings of the $11^{\text {th }}$ Vibrations in rotating machinery (VIRM 11); 2016 September 13-15; Manchester, UK.

[40] Ricci R, Chatterton S, and Pennacchi P. Robust estimation of excitation in mechanical systems under model uncertainties. J Sound Vib 2013;332(2):264-81. http://dx.doi.org/10.1016/j.jsv.2012.08.022. 